NBER WORKING PAPER SERIES

\title{
DID THE AMERICAN RECOVERY AND REINVESTMENT ACT HELP COUNTIES MOST AFFECTED BY THE GREAT RECESSION?
}

\author{
Mario J. Crucini \\ Nam T. Vu \\ Working Paper 24093 \\ http://www.nber.org/papers/w24093 \\ NATIONAL BUREAU OF ECONOMIC RESEARCH \\ 1050 Massachusetts Avenue \\ Cambridge, MA 02138 \\ December 2017, Revised October 2020
}

The authors thank seminar participants at the Federal Reserve Board, the College of William and Mary, the Federal Reserve Bank of Richmond, Miami University, Oberlin College, Vanderbilt University, University of Cincinnati, and conference attendees at the Midwest Macroeconomics Meetings. We thank August Graue for excellent research assistance. The views expressed herein are those of the authors and do not necessarily reflect the views of the National Bureau of Economic Research.

NBER working papers are circulated for discussion and comment purposes. They have not been peer-reviewed or been subject to the review by the NBER Board of Directors that accompanies official NBER publications.

(C) 2017 by Mario J. Crucini and Nam T. Vu. All rights reserved. Short sections of text, not to exceed two paragraphs, may be quoted without explicit permission provided that full credit, including (๑) notice, is given to the source. 
Did the American Recovery and Reinvestment Act Help Counties Most Affected by the Great

Recession?

Mario J. Crucini and Nam T. Vu

NBER Working Paper No. 24093

December 2017, Revised October 2020

JEL No. D31,E3,E62

\begin{abstract}
One of the statements of purpose of the American Recovery and Reinvestment Act (ARRA) was "to assist those most impacted by the recession." To consider this facet, the grants-in-aid portion of the ARRA is assessed from the perspective of fiscal federalism. We estimate a trend-stationary autoregressive model of county-level wage income dynamics where each county is subject to a common shock (with county-specific factor loading) and an idiosyncratic shock. We then ask if counties that experienced larger negative wage income shocks during the Great Contraction subsequently received more transfers per capita in the form of grants-in-aid. The fact that the negative business cycle shocks pre-date the passage of the ARRA and subsequent disbursements allows identification of the risk-pooling channel of the grants before fiscal multiplier effects confound these two channels. We find statistically significant and economically large risk-pooling effects.
\end{abstract}

Mario J. Crucini

Department of Economics

Vanderbilt University

Box 1819 Station B

Nashville, TN 37235-1819

and NBER

mario.j.crucini@vanderbilt.edu

Nam T. Vu

Miami University

Farmer School of Business

Economics Department

800 E. High St.

Oxford, OH 45056

vunt@miamioh.edu 


\section{Introduction}

The American Recovery and Reinvestment Act (ARRA) was signed into law by then-President Barack Obama on February 17, 2009. As a discretionary peacetime fiscal measure, the total appropriation was the largest in American history. The impetus for the stimulus was, of course, the collapse of the stock market and a rapidly deteriorating macroeconomic situation in the United States and abroad, at the onset of the Great Recession. Unfortunately, the appropriate policy prescription and dosage were impossible to determine with any reasonable degree of accuracy given the lack of consensus on the size of the fiscal multiplier, the economics profession was left in the unenviable position of having to assess the policy ex-post. This evaluation is ongoing and is proving to be a productive and challenging research area.

Much of the literature to date has focused on the question that macroeconomic models are best equipped to answer: How large is the expected change in GDP associated with an exogenous increase in federal government consumption? Empirical studies of the fiscal multiplier have a long intellectual history, recent work includes Feyrer and Sacerdote (2011), Wilson (2012), Chodorow-Reich et al. (2012), Nakamura and Steinsson (2014), and Dupor et al. (2018). A second branch of the post-ARRA literature has attempted to relate the stimulus to job creation (see, for example, Goodman and Mance (2011), Conley and Dupor (2013), Bohn (2013), and Dupor (2014)). ${ }^{1}$ Finally, a handful of papers deal with the subtle interactions of federal stimulus, and fiscal spending and taxation, at the state and local levels (see, for example, Johnson (2009), Cogan and Taylor (2010), and Leduc and Wilson (2017)).

Each of these studies has improved our understanding of fiscal policy and the role that specific parts of the ARRA stimulus package may have played in altering the paths of aggregate GDP and employment relative to a counterfactual without it. Largely absent from the literature is a systematic analysis of the heterogeneous impact of the Great Recession across locations within the country and the role the ARRA may have had in mitigating or exacerbating geographic income inequality arising from the Great Recession.

1) There is another related literature that deals specifically with the political economy aspect of the ARRA program. See, for example, Inman (2010), Gimpel et al. (2012), and Boone et al. (2014). 
Our work aims to help fill this gap in the literature by focusing on the second and fifth of the five stated purposes of the ARRA: (1) to preserve and create jobs and promote economic recovery; (2) to assist those most impacted by the recession; (3) to provide investments needed to increase economic efficiency by spurring technological advances in science and health; (4) to invest in transportation, environmental protection, and other infrastructure that will provide long-term economic benefits and (5) to stabilize State and local government budgets, in order to minimize and avoid reductions in essential services and counterproductive state and local tax increases. $^{2}$

To address the success or failure of the legislation along the dimension of changes in income inequality, arising from the Great Recession, requires that we move from an analysis of the macroeconomic impact to the microeconomic impact - from a focus on the time series movements in national income per capita to movements of county-level income relative to the national aggregate. Risk-sharing theory coupled with the theory of fiscal federalism provides the relevant benchmark for understanding these types of policy choices.

Assessing the effectiveness of the ARRA in mitigating income inequality is empirically demanding, requiring microeconomic panel data on both income and ARRA disbursements. These considerations led us to the Quarterly Census of Employment and Wages, which ensures a nationally comprehensive accounting of wage income with a frequency of observation conducive to business cycle analysis. As a consequence, the focus is on location-specific, not individualspecific, risks. Individual-specific risks will be averaged out as individual wages are aggregated to the county level. The basic implication of risk-sharing in this setting, then, is that more ARRA funds should be disbursed to counties that experienced larger income shocks during the contractionary phase of the Great Recession.

A necessary, but not sufficient condition for the ARRA to achieve this goal is that disbursements vary across counties. Establishing this fact is challenging because the ARRA was a complex mix of tax changes, grants to state governments, and grants to other private and public institutions. Our focus on counties rather than states is intended to preserve as much of the 2) $111^{\text {th }}$ Congress, Public Law 5, Statute 115, page 123, U.S. Government Printing Office. 
cross-sectional income variance as possible to identify the risk-sharing channel. Strict adherence in linking ARRA disbursements to county-level economic distress requires that each line-item disbursement has an associated zip code. This leads us to focus mostly on grants, which are the lion's share of the discretionary, non-tax, component of the ARRA.

We have two sets of novel results. The first has to do with the properties of county-level business cycles relative to the aggregate U.S. business cycle. The second has to do with the relationship between discretionary transfers through grants-in-aid and the unexpected variation in county-level wage income.

A novel feature of our econometric model of county wage income dynamics is that it allows for two sources of business cycle heterogeneity: 1) differences in the variance of the county-specific shock to wage income; and 2) differences in the factor-loading on a common macro-shock to wage income. Notice that the common, macroeconomic, shock generates perfect collinearity of business cycles across counties, but some counties may have amplified or muted business cycles relative to the national average, based on their factor-loading parameter.

Turning to details, the half-life of a shock to wage income for the median county is reasonably short, 2.6 quarters, but ranges from 1.7 to 4 quarters at the $25^{\text {th }}$ and $75^{\text {th }}$ percentiles of the cross-county distribution of persistence estimates. The county-specific shocks have a median standard deviation of $2.97 \%$ with the corresponding range from $2.22 \%$ to $4.21 \%$. Not surprisingly, the macro-shock has a standard deviation that is much smaller than that of the median county-specific shock, 1.3\%. The estimated county-specific factor loading ranges from 0.6 to 1.3 for the interquartile range, indicating that some counties have dampened responses to the macroeconomic shock while others' are amplified. Notice that these macro-factor loadings, when combined with the standard deviation of the macro-shock, imply a range of variation at the county level, from $0.78 \%$ to $1.69 \%$. While interesting in their own right, these county-level income processes are essential when assessing the potential for monetary and fiscal policies to mitigate or exacerbate geographical income inequality at business cycle frequencies.

This paper conducts an evaluation of the discretionary component of the ARRA in helping counties most affected by the Great Recession. We ask if counties experiencing either larger 
county-specific shocks or greater sensitivity to the common macro-shock received more funds during the Great Recession.

Estimating a cross-county fiscal policy function, it is found that $7 \%$ of the macroeconomic component of private wages shocks is mitigated by the grants in aid and no significant offset is found for the county-specific component private wages. For public wages, the results are reversed; $13.5 \%$ of the county-specific shocks are offset while there is no offset of the macroeconomic component of public wages. We also show that aggregating the macroeconomic (common) shocks with the county-specific shocks or aggregating private and public wages leads to misleading inference about the role of the ARRA in offsetting the contractionary shocks of the Great Recession.

Our paper is related to the risk-sharing literature dealing with fiscal policy, most notably, Asdrubali et al. (1996). Their study focuses on the role of various automatic stabilizers in mitigating the variance of income growth across U.S. states and finds that 13 percent of the unconditional variance of gross state product output growth is smoothed by the federal government. However, because they focus on automatic stabilizers, they do not estimate unexpected changes to income but use raw growth rates instead.

This distinction is important: the discretionary appropriations in the ARRA were explicitly designed to overcome the perceived deficiencies of automatic stabilizers in the context of an extreme business cycle downturn. As such, unlike existing stabilizers, the stimulus was unprecedented in size and known to be a temporary measure. There was no expectation of a subsequent round of stimulus. In an interesting recent contribution, Oh and Reis (2012) study the ARRA with a focus on the redistributive components of the policy. Their focus is on the implication of incomplete markets (and other frictions, such as sticky prices) on the size of the aggregate multiplier, rather than the covariance between county-specific transfers and county-level income shocks, which is our focus.

The paper proceeds in the following way. Section 2 describes our data sources. Section 3 presents a detailed picture of the time series and cross-county variation in ARRA grants. Section 4 reports the estimates of county-level wage income dynamics. Section 5 discusses the theory 
of fiscal federalism and reports the estimation of the fiscal policy function relating grants-in-aid disbursements to county-level and macroeconomic wage income shocks experienced during the Great Recession. Section 6 conducts robustness analysis, such as the sensitivity of the policy function to the exclusion of the counties where state capitals are located. Section 7 concludes.

\section{The Data}

We use two data sources, one for county-level wages and the other for the county-level disbursements of grants-in-aid.

Our measure of nominal wage income is total quarterly wages, from the Quarterly Census of Employment and Wages (QCEW). As a considerable fraction of transfers is eventually disbursed to local school districts, some of our wage income specifications break total county wages into their private and public parts.

The wage measure used in the estimation of labor income dynamics is the logarithm of county-level nominal wage income divided by the product of the U.S. GDP price deflator and the county-level labor force: ${ }^{3}$

$$
w_{i t}=\ln \left(\frac{W_{i t}}{L_{i t} P_{t}}\right) \text {. }
$$

This real wage income per capita series is then seasonally adjusted and is referred to simply as wage income from here on. ${ }^{4}$ The cross-sectional unit for the QCEW is the county-level Federal Information Processing Standards (FIPS) code.

The second source of data consists of the grants-in-aid portion of the ARRA and is challenging to construct. We purposely exclude any funds where it is not possible to identify the end recipient based on their zip code, as this is necessary to evaluate the fiscal risk-sharing model at the most spatially granular level possible. The data on ARRA transfers were initially collected by William Dupor at the Federal Reserve Bank of St. Louis and were supplemented with additional data

3) For the implicit price deflator, we use the GDPDEF series from the St Louis' FRED, which is the implicit price deflator used to deflate nominal GDP. County-level labor force data are from the Local Area Unemployment Statistics.

4) The seasonal adjustment is performed using the X-13 package from the U.S. census at https://www.census.gov/srd/www/x13as/ applied at the quarterly frequency. We apply seasonal adjustments for each county $i$ individually. 
from the now-defunct Recovery.gov, a Federal government repository of all the ARRA data. Specifically, the data up to 2012:Q2 are drawn from William Dupor's website and are extended through 2013:Q3, with supplemental data from recovery.gov.

A great deal of care is taken to identify the local zip code to which an individual ARRA transfer is finally distributed, as opposed to the zip code of the headquarters of the awarded company or organization with the goal of identifying the individuals (or, more precisely, the counties) most affected by the disbursement. We use a combination of sub-award numbers, zipcodes of the sub-recipients that are crossed checked with available data on state, city, and federal ARRA expenditure to arrive at our measure of ARRA flow. ${ }^{5}$ These dollar amounts are then aggregated to zip code totals in each quarter and then aggregated across all zip codes within each county to arrive at our county-level panel of ARRA grants by recipient county. As there are about 42 thousand zip codes and more than 3 thousand counties in the United States, on average, there are 14 zip codes per county. In the final step, we transform the nominal ARRA transfer in the same manner as the nominal wage income flows, taking the log of real per capita quarterly flows.

\section{Overview of the ARRA}

This section begins with an overview of both the expenditure and taxation policies contained in the ARRA bill at the national level, before turning to a forensic analysis of the county-level disbursements in the grants-in-aid portion of the package.

\subsection{Aggregate Composition of the ARRA}

Not only was the ARRA the largest peacetime discretionary stimulus package, but it also involved a complex array of fiscal policy measures. The most instructive aggregate compilation of the impact of the ARRA on taxes, transfers, and Federal expenditures across time that we have encountered was produced by the Bureau of Economic Analysis. Table 1 reproduces most of the content of that compilation.

5) Details are contained in section $\mathrm{C}$ of the online appendix. 
The combination of tax cuts and expenditures produced a cumulative deficit over the period 2009:Q1 to 2013:Q1 of $\$ 787$ billion. As has been emphasized by Cogan and Taylor (2010), the expenditure side of the ARRA consisted mostly of transfers. This is obvious in Table 1: $77 \%$ of expenditures consisted of transfers ( $\$ 516$ billion in current transfer payments relative to $\$ 672$ in total expenditure). This is also why it has been so challenging to produce a direct estimate of the fiscal multiplier, only $\$ 43$ billion of the expenditures are direct current Federal consumption expenditures, as modeled in the fiscal multiplier literature. Another $\$ 17$ billion is gross investment, not Federal consumption and $\$ 79$ billion is capital transfer payments consisting of $\$ 50$ billion, mostly grants for highway and public transportation infrastructure and restoration plus $\$ 29$ billion in home-buyer tax credits and highly specialized grants for energy properties.

\section{[Table 1 Here]}

Of the transfer programs, it is important to distinguish transfers that are allocated based on well-defined policy functions that pre-date the ARRA from the more discretionary allocations, which is our focus. These existing transfer programs are colloquially described in the macroeconomics literature as automatic stabilizers. State unemployment programs (enhanced by $\$ 59$ billion in federal stimulus in the ARRA), for example, are prime examples. Benefits are provided upon a job separation, conditional on an individual actively seeking work. The wage income replacement rate and duration of benefits are precisely defined. Moreover, in normal times, the funding is via unemployment insurance premiums collected by employers and thus fit into the lexicon of risk-sharing as a social insurance program to mitigate wage risk associated with the external margin of wage adjustment, unemployment. Certainly, the variation in unemployment across counties will correlate with the distribution of unemployment benefits that states disperse. As such, it is not necessary to estimate a fiscal policy function to understand the covariance between cross-county unemployment incidence and the unemployment insurance payments that states make to their respective counties. By definition, any means-tested transfer payment to an individual will have a well-defined benefit formula attached to it.

This is not true of the grants-in-aid portion of the transfer payments, which is what makes 
them interesting to study formally. These are payments made principally to state and local governments who have considerable latitude in terms of the allocations. Educational grants, which amounted to $\$ 76$ billion, are prime examples. The Department of Education stipulated broad educational policies as a condition for states to receive funding based on a proportion of their populations. They also stipulated that the states should provide assurances of intent to return educational funding levels to those of fiscal year 2006 and maintain those funding levels from fiscal year 2009 to 2011. Notice that these funding guidelines would not apply on a county-by-county basis. However, all states supplement funding deficiencies at the local level with the objective of moving toward more equal funding per pupil statewide than local revenues might allow. Local funding deficiencies would be particularly acute during a contraction of the intensity experienced during the Great Recession. Some states have such equalization formulae embedded in their constitutions. Notice that this channel should manifest in the relationship between public sector wage shocks and ARRA transfers. This will motivate the distinction between unexpected changes in private and public wages in our policy function estimation.

The final category, temporary tax provisions, in the amount of $\$ 281$ billion are excluded from our analysis, but are briefly discussed here for completeness. About half of this amount funds the Making Work Pay program and related tax credits provisions. One component is a $6.2 \%$ individual income supplement up to $\$ 400$, with a phaseout dollar-for-dollar above incomes of $\$ 75 \mathrm{~K}$ (thus reaching zero at $\$ 95 \mathrm{~K}$ ). Almost all counties would have qualified for the same $\$ 400$ per capita tax cut, leaving no cross-sectional variation to relate to the risk-sharing channel that is our focus. ${ }^{6}$

We turn now to a description of the ARRA grants in terms of their timeline of disbursements and variation across counties.

\subsection{The Distribution of Grants-in-Aid Across Counties}

The purpose of this section is to document the extent to which per capita grants-in-aid transfers were unequal across counties. Toward this end, the upper panel of Figure 1 presents the cross-

6) Of course the within county income distribution would be needed to assess the within county redistributive effect of this tax policy. 
sectional distribution of the flow expenditure of ARRA grants-in-aid using a box and whisker plot for each quarter of our micro-data (2009:Q3 to 2013:Q3).

Beginning with the cross-county median disbursements (the horizontal lines in the shaded boxes), we see a gradual build-up in the first 5 quarters and then a tapering thereafter. By the first quarter of 2012, the flow has fallen to a negligible amount and remains there going forward. As measured by the median flows, the grants-in-aid are economically substantial in the first two years of the program, averaging about $1.5 \%$ of median income per quarter.

Also very evident is variation around the median. The interquartile range (shared area) is vast, ranging from a low of $\$ 21$ per capita to a high of $\$ 168$ in the third quarter of 2009 (this translates to a range of $0.2 \%$ to $1.3 \%$ of median flow income).

[Figure 1 Here]

The lower panel presents the cumulative flows by county and again presents the quarter-byquarter cross-sectional distribution in a box and whiskers plot. At the time the funds have been fully disbursed in 2013:Q3, the median county has received about $\$ 981$ per capita, which amounts to about $6.9 \%$ of median quarterly flow income, and is thus equivalent to a constant $0.43 \%$ of median annual income in flow terms, over the duration of the program. The interquartile range in 2013:Q3 is vast, $\$ 908$ dollars, or around 6.4\% of quarterly income.

Given our focus on county-level business cycles and risk-sharing, it is helpful to display the raw inputs to our fiscal policy estimation on a map. The upper panel of Figure 2, plots the cumulative wage income shocks (estimation details follow in the next section) from peak to trough based on the official NBER dates (2007:Q4 to 2009:Q2). There is, perhaps not surprisingly, considerable diversity of business cycle conditions across U.S. counties. More surprising, is the fact that a large number of - admittedly sparsely populated - counties that experience positive wage shocks during the Great Recession.

[Figure 2 Here]

The lower panel shows the cumulative ARRA transfers per capita. The median county thus received about $\$ 981$ per capita of transfers in total. This amounts to around $6.9 \%$ of the 
quarterly flow of income over this period, for the median county. Consistent with the earlier timeline of distributions there is enormous variation in the cross-section. Our focus is the relationship between transfers to counties and the unpredictable, cyclical movements in wage income. To get at this issue, one needs a model of county-level wage income dynamics, to which we now turn.

\section{County and National Business Cycles}

As far as we know, there has been no systematic study of county-level business cycles or their relationship to the national business cycle. This section intends to fill this gap as a necessary preliminary step to estimating a fiscal policy function at the county level.

\subsection{Wage Income Specification}

Our preferred specification is a trend stationary model at the national and county level of aggregation. This is consistent with the view that policymakers at the national level aim to reduce cyclical variation in U.S. output relative to its historical trend growth rate. ${ }^{7}$

Beginning with a representative county, $i$, real wage income per capita is assumed to follow:

$$
w_{i t}=\alpha_{i}+\gamma_{i} t+\Gamma_{i} t^{2}+\rho_{i} w_{i, t-1}+\lambda_{i} \varepsilon_{t}+\varepsilon_{i t}
$$

The presence of lagged wage income captures the well-known feature of macroeconomic data that departures from trend growth tend to be positively correlated over time (i.e., we expect $\rho_{i}>0$ ). Here, persistence is allowed to vary across counties. While we find a strong central tendency in the persistence parameter across counties, as a practical matter, leaving them unrestricted helps to ensure that forecast errors are not biased by arbitrarily assuming a common persistence level across structurally diverse counties.

7) An earlier version of this paper also examined difference-stationary specifications and found evidence of over-differencing. Moreover, first-differencing is known to exacerbate measurement error, particularly in finely disaggregated data. This would lead to significant attenuation bias in the fiscal policy estimates where shocks to income are the regressors. 
Notice that the residual in this regression, $\varepsilon_{i t}$ is indexed by county $i$ and period $t$, the same two dimensions of the data panel itself. Obviously, this is a mechanical implication of panel econometrics: there will always be unexplained variation at the unit of observation, thus $\varepsilon_{i t}$ is completely standard. The more novel and interesting facet of the specification is the presence of the common shock, $\varepsilon_{t}$, which carries a county-specific factor loading, denoted by $\lambda_{i}$. In words: the common shocks shift the entire cross-county wage distribution, generating perfect multicollinearity among all counties. Factor loadings exceeding 1 indicate an amplified business cycle response to a common shock while values less than 1 indicate dampening. It is worth noting that negative factor loadings, which would identify counties with local business cycles that are counter-cyclical to the national business cycle, are rare.

The common shocks are estimated from a first-stage regression using the average of $w_{i t}$ across the entire distribution of 3,133 counties. The cross-county average is denoted by $w_{t}$. The empirical specification for the average wage takes the same functional form as that of an individual county:

$$
w_{t}=\alpha+\gamma t+\Gamma t^{2}+\phi w_{t-1}+\varepsilon_{t}
$$

Equation (2) provides a natural benchmark with which to estimate the common, macroeconomic shock, $\varepsilon_{t}$, that shifts the mean of the county-level wage income distribution. Notice, if the persistence parameters are the same across counties in equation (1), the county-level specification aggregates exactly to produce equation (2), with the factor loading parameters averaging to unity across counties and the county-specific shocks averaging to zero. This is not just a theoretical curiosity, it appears to be the case in practice: the persistence of the mean wage income process, $\phi$, is 0.75 , indistinguishable from the persistence of the median county at 0.77 . The average and median of the factor loadings are indistinguishable from 1, at 0.99 and 1.01, respectively.

Turning to the details, we estimate this pair of equations for each county using OLS with Newey-West robust standard errors to account for potential auto-correlation and heteroscedasticity in the error terms. In the first step, we estimate the aggregate wage income equation (2) and save the estimated common shocks $\varepsilon_{t}$. Then, we estimate (1) county-by-county, inserting 
the estimated common shocks, $\varepsilon_{t}$, from the first step.

This two-step process has the desirable feature that the common shock is orthogonal to the county-specific shock. The upshot is that counties now have two sources of wage income risk: 1) one due to cross-county heterogeneity in county-level wage responses to the common shock, $\lambda_{i} \varepsilon_{t}$, and 2) one due to the county-specific shocks, $\varepsilon_{i t}$.

Note, some care should be taken when interpreting the county-specific shock. While this shock has the desirable property that it is orthogonal to the common shock by construction, the pairwise correlations of $\varepsilon_{i t}$ structure are left unrestricted. To be concrete, consider the recent fracking boom. Over the last few decades, an increasing number of counties have become substantially dependent on wage income from fracking. This inevitably gives rise to a common shock, within the sub-group of counties highly dependent on fracking income, not shared by other counties. At the same time, as a sufficiently large number of counties engage in fracking, the general equilibrium impact of the aggregate fracking boom, while raising relative wages in fracking counties, could lower the GDP price deflator, through energy price declines, for both fracking and non-fracking counties. This equilibrium effect would be part of the common shock and would be expected to have a much larger loading on the counties directly earning wages from fracking, compared to those benefiting indirectly from the positive spillover of lower energy prices.

Our two-step approach recovers several parameters and shocks of potential interest: 1) the intercept $\left.\alpha_{i} ; 2\right)$ the linear and quadratic trend coefficients, $\gamma_{i}$ and $\left.\Gamma_{i} ; 3\right)$ the persistence of the county-level wage income process, $\left.\rho_{i} ; 4\right)$ the factor loading on the common shock, $\left.\lambda_{i} ; 5\right)$ a historical sequence of estimated common shocks, $\varepsilon_{t}$; and 6) a historical panel of county-specific shocks, $\varepsilon_{i t}$.

Our use of the phrase 'of potential interest' is intentional. Our focus on business cycle variation leads us to treat the trend terms as nuisance parameters, needed to induce stationary in real wage incomes. The constants are also not very interesting unless the trends are equal, or approximately so, in which case they translate into estimates of long-run wage income differences across counties. For these reasons, the discussion that follows will focus on the persistence 
parameters, the factor loadings, and the shock sequences. ${ }^{8}$

\subsection{Estimation Results}

Turning to the estimation results, Table 2 summarizes the parameter estimates: both their averages across counties and the extent of heterogeneity across counties.

The median county has a wage income persistence of 0.77 (a half-life of about 2.65 quarters). As might be expected, there is considerable variation in persistence around the median: from 0.66 to 0.84 , based on the $25^{\text {th }}$ and $75^{\text {th }}$ percentiles of the estimated distribution. These estimates translate into half-lives with a range of 1.69 quarters to 3.97 quarters.

\section{[Table 2 Here]}

As first emphasized by Baxter and Crucini (1995), what is important from a welfare perspective when comparing locations - in their case, nations, in our case, counties - is the persistence of the productivity gap. The productivity gap (holding fixed inputs of capital and labor) maps directly in the relative income and wealth effects through the intertemporal budget constraint. Moreover, high persistence in the labor productivity gap has two effects. On the capital accumulation side, it makes reallocation of capital more compelling than the case of highly transitory shocks. This amplifies the wealth effects of the productivity movements across locations. On the labor input side, more persistence tends to bring about more balance in the wealth and substitution effects of labor supply decisions. ${ }^{9}$

In our context, the gap in persistence based on the estimated inter-quartile range is only 0.18 (0.84-0.66 for total wages) which translates into a predicted wage income gap of only $3.2 \%$ after just one quarter following a common $10 \%$ income shock. In summary, persistence heterogeneity appears not to be an important quantitative feature of the sources of gains from risk-pooling across counties.

8) The full distributions of the parameter estimates across counties are presented in a series of kernel density estimates in the estimation appendix.

9) Note that these differences are likely to be magnified in the context of the Great Recession due to the financial shocks that negatively impact the ability of agents to pool risk through credit markets (see, for example, Perri and Quadrini (2018)). 
The heterogeneity of business cycle experiences across counties, therefore, falls to differences in the factor loadings on the common shock and the variability of the county-specific shocks. The county-level parameter estimates indicate that both of these stochastic features are important sources of business cycle heterogeneity across counties.

For the median county, the standard deviation of the idiosyncratic shock is $2.97 \%$ (Table 2). The median factor loading $\left(\lambda_{i}\right)$ on the macroeconomic shock is indistinguishable from unity at 1.01. This, combined with the fact that the common (macroeconomic) shock has a standard deviation of $1.3 \%$, implies that for the median county, the microeconomic shocks account for two-thirds of the variation, while the macroeconomic shock accounts for the remaining one-third. Keeping in mind that the county-specific shock is likely to contain measurement errors which are averaged away in the construction of the macroeconomic shocks, the estimated contribution of the microeconomic shock might better be viewed as an upper-bound.

There is considerable county-level heterogeneity in factor loadings and county-specific shock variances. Beginning with the microeconomic shock $\left(\varepsilon_{i t}\right)$, the standard deviation ranges from $2.22 \%$ to $4.21 \%$, a factor of 1.9 . The factor loadings on the common shock $\left(\lambda_{i}\right)$ range from 0.6 to a high of 1.35 (moving from the $25^{\text {th }}$ to $75^{\text {th }}$ percentile cutoffs). In words, a negative $5 \%$ macroeconomic wage income shock (comparable to the Great Recession) would induce a $3 \%$ decline in county-level wages in the former case and a $6.75 \%$ wage decline in the latter case. This parameter range is a factor of about 2.1, slightly greater than the cross-county heterogeneity found in volatility associated with the county-level shocks.

As part of our robustness analysis, we consider a split of wage income into private wage income and public wage income. Due to some inconsistencies in the reporting of public wages by county in the QCEW, we compute total public wage income as the difference between total county wage income and total private wage income. Estimates of the parameters for the stochastic processes for private and public wages by county are also reported in Table 2 . What is most notable about the split is that the parameters and shock variances are actually quite similar across the private and public sectors. As one might expect, the innovations to private and public wages tend to be more volatile than the two combined, indicative of some diversification benefits of having both 
income streams in the county. In the lower panel, we see the standard deviation of total wages has a cross-county median of about $3 \%$, while private and public wages have standard deviations of about $3.5 \%$ each.

\subsection{Forensic Analysis of the Great Contraction}

Our identification of the fiscal federalism and risk-sharing channel will exploit the timing of the contraction relative to the passage of the ARRA and disbursement of funds. This will be discussed further in the next section.

To get a sense of the cumulative misery brought about by the Great Recession across counties, Figure 3 presents the distributions of the cumulative wage income shocks by type of shock and wage measure. The top panel shows the cross-county distributions of common and county-level shocks, in red and gray bars, respectively. The lower two panels are the shocks estimated from the private and public wage series, when estimated separately.

[Figure 3 Here]

Beginning with total wages, the cumulative shocks over the Great Recession amounted to $-4.6 \%$, while the corresponding values for private and public wages were $-8.8 \%$ and $+2.8 \%$, respectively. These cross-county means are clearly visible in the central tendencies of the crosscounty distributions of the common shocks. The fact the public wages were, on average, above trend during the contraction is interesting and, as we shall see, gives rise to an implication that transfers are positively correlated with the common shock component of public sector wages.

The county-level shocks are very close to mean zero across counties though considerably more dispersed than the factor loadings on the common shocks (i.e., the dispersion of wage income associated with the common shock). The county-level shocks for public wages are evidently much more compressed than their private counterparts. This could reflect the fact that while school districts are institutionally organized on a county level, teachers' unions exist at the state and the national level. 


\section{Fiscal Federalism}

The theoretical concept of fiscal federalism covers a range of fiscal issues spanning political jurisdictions, but a key element involves transfers from the national government to sub-national governments. From the perspective of the question posed in this paper concerning risk-sharing, these transfers should be place-based and state-contingent. That is, they should help counties most affected by the Great Recession.

\subsection{What is Fiscal Federalism?}

The most transparent example of fiscal federalism is Canada's system of equalization payments from the national government to the provincial governments. Effectively, equalization payments transfer federal funds from provinces with higher fiscal capacity to those with lower fiscal capacity. In the Canadian system, there is both a long-run equalization effect and a business cycle effect. That is, equalization payments, when averaged over time will reflect the permanent inter-provincial income inequality and will thus reduce the dispersion of wage income in the long run. ${ }^{10}$ Equalization payments in any given year, relative to these long-run means, will be a function of the relative movements of wage income (and thus tax revenue and fiscal capacity) across provinces in that year. For example, energy prices are of enormous influence given the concentration of the oil sands in the provinces of Alberta (and to some extent Saskatchewan). These provinces have higher income, on average, over time compared to other provinces, but much more so when oil prices are over $\$ 100$ per barrel than at less than $\$ 50$.

Thus, from the perspective of helping counties most affected by the Great Recession, conceptually the appropriate model is the state-contingent transfer system associated with fiscal federalism. That is, to assess the potential role of risk-pooling through fiscal federalism we must determine how relative economic conditions across U.S. counties enter into the determination of the transfers they receive.

From a rational expectations perspective, this leads to a pernicious identification issue similar

10) The reduction in post-transfer income inequality requires that the distortionary effects not outweigh the direct effects of the transfers and thus hinge on the magnitude of equilibrium wealth and substitution effects. 
to that faced when economists estimate the reverse regression, with changes in GDP on the left-hand side and changes in government consumption on the right-hand side. That is, when attempts are made to estimate the fiscal multiplier. We turn, now, to a discussion of this issue and how we propose to resolve it in the context of the ARRA.

\subsection{Identification}

In the fiscal multiplier context, when output falls unexpectedly due to an unidentified (or partially identified) shock, the unconditional covariance between changes in output and government spending suffers from negative simultaneity bias. The negative macroeconomic shock induces a discretionary increase in government consumption. Causation runs from the business cycle shock to the policy response. Government consumption, in turn, may have mitigated the impact of the shock. Causation also runs from government consumption to wage income. With causation running in both directions, simply regressing the change in output on the change in government consumption, the fiscal multiplier is downward biased (assuming the true impact of an exogenous change in government consumption on wages positive). This line of reasoning leads to the common claim: "things would have been worse in the absence of the fiscal stimulus."

The grants-in-aid are transfers to state and local governments (as well as to non-profits and firms), not Federal government consumption, so they clearly increase the level of financial resources in a county relative to when they are absent. This is, of course, our and Dupor (2014)'s rationale for conducting a forensic analysis of the allocation of ARRA transfers to individual counties and over time. Without accurate tracking, the income effects of the transfers will not be attributed to the correct recipient, or in our case, the correct county. Moreover, once

the funds are spent on goods and services, the subsequent indirect economic effects via the traditional fiscal multiplier will also not be correctly identified in terms of the final expenditure multipliers. The issue is further complicated by the fact that the ARRA policy (as described in the state objectives) calls for a response to both an aggregate shock and a local shock with the final expenditure rarely taking the form of homogeneous federal consumption (e.g., military spending). 
As it turns out, this particular episode in U.S. history presents something of a natural experiment in fiscal federalism. As a matter of fact, the contractionary phase of the Great Recession predates the passage of the stimulus bill. Moreover, the actual disbursement and expenditure of funds occurs with even greater delays, beyond the business cycle trough, as they are typically based upon discretionary decisions by the primary (often the state government) and secondary recipients. This timing structure provides our identification strategy whereby the policy function determines the post-recession cumulative allocation of grants-in-aid received by an individual county as a fraction of the cumulative unexpected declines of wage income experienced by that same county, during the contraction. ${ }^{11}$ We call this a fiscal federalism offset, or fiscal offset, for short.

[Figure 4 Here]

The fact that the negative wage income shocks pre-date the ARRA stimulus package and the flow of transfers is clear from Figure 4. The upper panel presents the distribution of wage shocks across counties and over time. The dark red solid line is the median shock across counties, the dark shaded area is the inter-quartile range of shocks and the light red shaded area is the distribution of the shocks from the $5^{\text {th }}$ percentile to the $95^{\text {th }}$ percentile. For completeness and ease of presentation, the shocks displayed here are the composite of the macroeconomic and the microeconomic shocks, $\lambda_{i} \varepsilon_{t}+\varepsilon_{i t}$, which we call the composite shock in what follows.

The lower panel shows the distribution of grants-in-aid disbursements to the counties (the lines and color-coding follows those of the upper panel). These disbursements, too, were discussed earlier in great detail. The key takeaway here, however, is the timing of transfers relative to the negative wage income shocks. Remarkably, the contractionary phase (the shaded area) of the Great Recession is basically complete at the time the ARRA funds begin to flow.

Our fiscal risk-sharing policy function exploits this timing sequence by regressing the cumulative post-contraction transfers to each county from 2009:Q3 to 2013:Q3 on the cumulative

11) An earlier version of this paper used contemporaneous transfers and business cycle shocks throughout the disbursement period of ARRA. We are grateful to the editor, Vincenzo Quadrini, and an anonymous referee for pressing us to develop a more effective identification strategy. 
income shocks during the contraction, 2007:Q4 to 2009:Q2. Since the timing of disbursements and their cross-county distribution were not known at the time of U.S. business cycle contraction, the wage income shocks during the contraction are exogenous to the post-contraction ARRA transfers. With this one-way causality from past wage income shocks to future transfers, we are able to answer the question posed in the title.

\subsection{Fiscal Policy Function Specification}

With this identification approach in hand, we turn, now, to the estimation of the fiscal risksharing policy function. Our benchmark policy function allows for a different elasticity with respect to the common shock and the county-specific shock:

$$
T_{i, L}=\alpha+\beta_{M}\left(\lambda_{i} \varepsilon_{L-1}\right)+\beta_{m} \varepsilon_{i, L-1}+\nu_{i} .
$$

Here the subscripts $L$ and $L-1$ are to remind the reader that policymakers allocate future ARRA transfers based upon past income shocks. Specifically, the estimated income shocks (from the panel wage income model) are summed over the NBER dated Great Contraction from 2007:Q4 to 2009:Q2 (denoted using the subscript $L-1$ ), while the transfers $T_{i, L}$ are the natural logarithms of the real per capita totals paid out to county $i$ from 2009:Q3 to 2013:Q3 (denoted using the subscript $L$ ).

It is worth emphasizing that, the precise timing of shocks and transfers in each of these two windows simply does not matter for the question that we ask. Only the totals matter. Given that nominal interest rates are near zero, this could equivalently be thought of as a comparison of the negative county-level wealth effects brought on by the economic contraction and the partially compensating (i.e., positive) wealth effects of the federal transfers. This stands in stark contrast to the question of what effect the transfers and the timing of actual expenditures have on wage income dynamics within and across counties during the recovery phase. Clearly, answering that question is more complicated, and arguably, empirically intractable. 
More elaborate specifications are also considered, including:

$$
T_{i, L}=\alpha+\beta_{M}^{s}\left(\lambda_{i}^{s} \varepsilon_{L-1}^{s}\right)+\beta_{m}^{s} \varepsilon_{i, L-1}^{s}+\nu_{i}^{s},
$$

where $s$ indexes either the private or public sector and thus allows for sector-specific shocks of each type. Note that both the factor loadings and the policy response coefficients are also sector-specific.

Finally, we also estimate a policy function with all four sources of shocks included (private common, private county-specific, public common, and public county-specific). The policy function with all the types of shocks allows a somewhat greater amount of the transfers to be explained, but the coefficients of the policy function remain largely unaffected because the shocks are not highly correlated across counties.

In reporting estimation results, the estimated coefficients are standardized in the usual sense: they indicate how a one standard deviation wage income shock moves transfers in units of its standard deviation. Of course, the transfers still have the interpretation of a percentage offset of the negative wage income shocks during the contraction, in the total income of the county. The standardization makes it clear that the policy function is an elasticity with respect to the shock and does not depend on the scale of the shock. This can be seen by noting that without standardized coefficients, if one multiplies the factor loading by a larger macroeconomic shock $\left(\varepsilon_{t}\right)$, the effect on a non-standardized coefficient will be to reduce the slope parameter by the same proportion. Whereas with the standardized coefficient, the slope parameter is invariant to the size of the shock.

The same logic reveals an additional, desirable, feature of our approach. The identification of the elasticity of the transfer policy function with respect to the macroeconomic shock arises exclusively from the covariance of $\lambda_{i}$ and $T_{i L}$. Since the factor loadings are historical features of the cross-sectional county wage income process, they are not parameters that are endogenous to the ARRA transfers themselves. This provides an additional source of identification for the redistributive role of the transfers. Note, that the same is not true of the microeconomic shock 
and thus the timing convention we employ remains crucial from that perspective.

What then is the role of the macroeconomic shock? First, the sign of the shock is important since transfers are strictly positive. So, the expectation is a negative coefficient such that when the economy is contracting, positive transfers are made. Second, the size of the common shock determines the size of the appropriation necessary to provide the proportional offset. Third, the more afflicted the county is by the common shock (i.e., the larger is $\lambda_{i}$ ), the higher is the absolute size of the per capita transfer.

Sensibly, if the macroeconomy is not in a recession, in the sense that $\varepsilon_{t}=0$, there is no justification for discretionary spending, associated with the common shock. No aggregate appropriation. There will still be purely redistributive transfers to offset the county-specific shocks. This is what happens in general with fiscal federalism, as in the case of Canada. Provinces contribute different amounts to national tax revenue streams given the conditions of their economies and the federal taxes they remit and the equalization payments represent net-zero aggregate transfers and thus a vector of positive and negative transfer payments on a province-by-province basis.

In the U.S. case, this would only be operative for discretionary spending when the appropriation is explicitly intended to redistribute, which is just one of the stated goals of the ARRA. Thus, we can think of the ARRA as the first historical experiment in fiscal federalism by the U.S. federal government and the estimated policy function is only appropriate for the Great Recession.

Notice that, by definition, the idiosyncratic shocks average toward zero across counties and thus define a set of taxes and subsidies that net to zero within each quarter. In contrast, the transfers associated with the macroeconomic shock are strictly positive (since, as we shall see, the betas are negative). That is, grants add to the Federal deficit during the Great Recession due to the offset of macroeconomic shocks $\left(\lambda_{i}\right)$. These deficits would need to be financed using some combinations of future tax increases and spending reductions. Whatever the excess burden of the ARRA may be (due to these deficit-balancing actions), the point of this paper is to determine if the current beneficiaries are those most affected by the Great Recession.

Thus $\beta_{M}<0$ is the percentage offset of the cumulative effect of the common shock on county 
$i{ }^{12}$ Notice that the cumulative effect on the median (or average) county is, quite sensibly, just the cumulative shocks experienced by the aggregate economy (i.e., $\lambda_{i}=1$ on average). However, the dollar offset is larger (smaller) in absolute terms for counties that amplified (muted) responses to the common shock, $\lambda_{i}>1\left(\lambda_{i}<1\right)$.

Turning to the microeconomic shock, the cross-county income variance brought about by the sequence of microeconomic shocks during the Great Contraction is $\varepsilon_{i, L-1}$. Adding the transfer flows to these shocks gives us: $\left(1+\beta_{m}\right) \varepsilon_{i, L-1}$. Thus, $\beta_{m}<0$ is the percentage offset of the cumulative microeconomic shocks experienced by county $i$ during the contraction.

Understanding the risk-sharing facet of the offset requires a focus on the second moment of the distribution of the shock distribution. Consider, again, the common shock. During the contraction, total wage income fell, on average (across counties), by $4.9 \%$. The dispersion arises not from the shock, but from the implications of the shock given the heterogeneity in factor loadings. Simply put, the conditional variance of income across counties brought about by the common shock is $\operatorname{var}_{i}\left(\lambda_{i}\right)$ multiplied by the square of the shock. In contrast, for the microeconomic shock, the mean across counties is zero. It is the dispersion of the $\varepsilon_{i, L-1}$ across $i$ that determines the change in wage income dispersion arising from these shocks, during the contraction.

\subsection{Estimation Results}

We turn, now, to the policy function estimates. Keep in mind, as discussed in the previous section, the estimated coefficients in the table are standardized.

Table 3 reports the results of the policy function estimation. The top panel uses the shocks recovered from total wages, the middle panel uses the shocks recovered from private wages and the bottom panel uses the shocks recovered from public wages. ${ }^{13}$ Bootstrapped standard errors

12) In principle, we could make a small adjustment to account for the fact that the present value of the disbursements is lower when discounted back to the period of the shocks. We choose not to do so because the adjustment would be small and somewhat arbitrarily assume a common discount rate across counties. Thus we prefer the more transparent comparison of simple cumulative real per capita values across relatively proximate periods without arbitrary adjustments for discounting flows.

13) In all specifications, zero-dollar ARRA transfers are replaced with a small positive value to avoid taking the $\log$ of zero. Excluding the zeros has very little impact on the coefficients of the estimated policy function. 
are reported to account for the use of generated regressors (i.e., the estimated shocks from the wage income estimation).

\section{[Table 3 Here]}

We use the term fiscal offset to refer to the coefficients on the policy function. The intuitive rationale is that the coefficient represents the proportional change in cumulative county wage income shocks during the contraction that is offset by cumulative flows the county receives under the ARRA. This gives a well-defined answer to a well-defined question.

Beginning with total wages in the top panel of the table, the first row shows the fiscal offset coefficient to be $-10.3 \%$; that is, a $10 \%$ "shock" at the county level will be reduced to $8.97 \%$. The next two rows separate the common (macro) shock from the idiosyncratic county micro shock. The value of distinguishing the two shocks is immediately evident since the offset of the common shock is 1.6 times that of the offset of the county-specific shock, $-13.7 \%$ versus $-8.5 \%$ (column 3). The last column includes both shocks in the same policy function. The coefficients are very similar to the case when they are estimated in separate regressions, due to the fact that, period-by-period, the county-specific shock is orthogonal to the common shock. ${ }^{14}$

If the private and public sectors experience different shocks, then it is important to consider if the policy function is misspecified when they are aggregated together. This possibility is easily accommodated by the fact that we estimated separate wage equations for the private and public sectors. These policy function estimates are presented in the middle and lower panels of Table 3.

Beginning with the composite private shock and composite public shock, we see that for private wages the coefficient is now indistinguishable from zero while the coefficient for the composite public wage shock is negative, economically and statistically significant, and comparable in magnitude to its counterpart for the results using the aggregate wage, $-12.5 \%$ offset predicted versus $-10.3 \%$ in the first row of panel A. While it is tempting to suggest that this shows that the public sector and not the private sector benefited from the transfer policies, this is not an 14) Readers familiar with omitted variable bias will appreciate this demonstration of unbiasedness in the context of omitted, uncorrelated, regressors. 
appropriate conclusion for the same reason it was inappropriate in panel A. The coefficient on the composite shock obscures the separate policy responses to the macro shock and the micro shocks, which we now have estimated for both the private and public sectors.

Turning to the macroeconomic shock, we see that there is an economically and statistically significant offset for private wages, $-6.9 \%$, but no offset for the common public wage shock (0.017). Put differently, the coefficient on the common shock suffers from bias due to sector-level heterogeneity. With the benefit of hindsight the coefficients on these two separate common shocks seem obvious since as was shown in the income estimation section, private wages experience a series of negative shocks during the contraction while public wages experience a series of positive shocks during this same contraction. That private and public wages have different signs of cumulative shocks, on average, is itself interesting and novel. The consequence is that they cannot then carry the same coefficient when being related to the same distribution of transfers. As it turns out, the fiscal offset works to mitigate the large common negative shocks to private wages but not the small common positive shocks to public wages.

Interestingly, the role of private and public microeconomic shocks mirrors the results for the common macroeconomic shocks. The fiscal offsets are zero for the county-specific private wage shocks and strongly negative, $-13.1 \%$ for the public county-specific wage shocks.

[Table 4 here]

To further check on the sensitivity of our estimated policy function, we estimate the policy functions with all four shocks separately included in the same policy function. Specifically, we estimate the following regression:

$$
T_{i, L}=\alpha+\beta_{M}^{\text {Private }}\left(\lambda_{i} \varepsilon_{L-1}\right)+\beta_{m}^{\text {Private }} \varepsilon_{i, L-1}+\beta_{M}^{\text {Public }}\left(\lambda_{i} \varepsilon_{L-1}\right)+\beta_{m}^{\text {Public }} \varepsilon_{i, L-1}+\nu_{i} .
$$

As is evident from Table 4, our policy function estimates are consistent, both in terms of the magnitudes and their statistical significance, with the benchmark estimates in Table 3. The key insight of this analysis is that it is important to not aggregate private and public wages, nor the components of the shocks to each wage income stream. 


\subsection{Discussion}

The final estimation results in Table 4 demonstrated the need to parse the shock distribution into four components. The first two components are the common shock to the private sector and the common shock to the public sector. These two shocks, by construction, generate perfect collinearity across counties within the same sector, but not across sectors. This distinction is clearly important in the context of the Great Recession, when the private wage distribution shifts strongly downward (-8.8\% on average) while public distribution moves modestly upward $(2.8 \%$ on average). From a risk-sharing perspective, this pattern of shocks should have induced transfers from the public sector to the private sector. While we do find strong offsets accomplishing the mitigation of private-sector wage declines in the aggregate, this is not coming at the expense of the public sector, which carries a zero coefficient on their common shock. The implication is that the transfers to the private sector are being financed by the current deficits: some combination of future tax increases, and/or spending and transfer cuts.

Given the negative offset on common shock component of private wages, it follows that counties with more amplified private-sector wage income responses to the Great Recession (higher $\left.\lambda_{i}\right)$ are getting larger absolute transfers. This type of policy is consistent with the tendency for the federal government to come to the rescue of companies in more cyclically sensitive industries, such as the bailouts of GM and Chrysler in late 2008. Keep in mind, however, those corporate bailouts are separate from the grants-in-aid. The estimated policy function suggests the same mechanism is operative more broadly.

What of the microeconomic shocks? On the private sector side, the policy coefficient is zero. Is this surprising? We think not. Firms would have had to make their state governments aware of their relative economic position in order to gain their relative share of the transfer payments. It seems plausible to us that given the idiosyncratic nature of these county-specific shocks, it is unlikely that these firms would have the lobbying power to skew grants in their direction. Reinforcing this argument is the fact that most firms of significant economic size will have economic activities that span more than one county, often many more than one. Addressing this issue is quite distinct from our risk-sharing focus and is empirically intractable as it would 
require aggregating the grants-in-aid by firm size and considering the shocks impacting firms based on their sector of specialization and geographic reach.

On the public sector side, the mechanisms are very different. Given the large component of education funding in the stimulus package and the fact that all state governments have a responsibility to keep educational funding per pupil more equal, it is natural that revenue shortfalls in various school districts should be met with redistributive transfers that depend on their relative economic conditions. Moreover, since K-12 school districts are typically organized along county lines, our spatial aggregation is particularly well suited to identify this facet of the ARRA.

\section{Robustness}

This section reports additional results that alter our benchmark analysis in a number of ways to check on their robustness and our interpretations of the findings.

\subsection{Sensitivity Analysis: Allocations of Grant-in-aid}

An important contribution of our paper is tracking the funds appropriated by the U.S. Congress all the way to end recipients at the zip-code level. The process by which this occurs starts with the Federal Agencies and Departments charged with their specific appropriations and more often than not involves delegation to state and local governments to intermediate the process with considerable discretion about the details. Inevitably, there are delays in the movement of funds from the state level and beyond. At times, there is less than complete or accurate reporting of the allocations. This leads to the potential for geographic misallocation of funds in the panel data.

To consider this possibility, we explore the extent to which the estimated parameters of the policy function are sensitive to leaving counties out of the panel estimation, one at a time. Given the large appropriations allocated to state capitals and the dominant role of state governments in subsequent allocations, we also consider the implications of leaving out all counties in which a state capital resides. 
The re-estimated coefficients, presented in Figure 5, are normalized by the corresponding estimates using the full sample in Table 3. Thus, a value of 1.01 means the coefficient is $1 \%$ higher when a county is left out of the pooled estimate. The distribution of the resulting estimates is presented both in the form of histograms and smoothed kernel density estimates in Figure 5.

Overall, we find that our benchmark estimates are basically invariant to the exclusion of a randomly chosen county. The aggregate fiscal offset (panel A) has a median value of around 1.001, with the majority of these "leave-one-county-out" estimates remaining close to the median (most of the estimates range between 1 and 1.005). This result implies that leaving out counties, one by one, does not have a material effect on the policy function estimates. In panels B and C of Figure 5, it is also clear that the offset coefficient for common shocks to private wages and to microeconomic shocks to public wages are robust to leaving out counties one by one.

We next turn to the counties in which the state capitals are located. The estimates for the samples that leave out all state capitals are presented as the vertical lines in Figure 5. Here the estimates are once again adjusted by the corresponding benchmark with the full sample. As is evident in Figure 5, the coefficients are, again, virtually unaffected: leaving out the capital counties only skew our estimates by at most $3 \%$ for the case of composite fiscal offsets.

[Figure 5 Here]

\subsection{Fiscal Offsets and the Sizes of ARRA Transfers}

We next explore the extent to which our estimates of the effects of the ARRA program in offsetting income shocks at the county level are sensitive to the size of the transfers. To that end, we estimate specification (1) of Table 4 and report the estimates of the common, and county-level policy functions for private, and public wages at different quantiles $\left(10^{\text {th }}\right.$ to $\left.90^{\text {th }}\right)$ of the per capita transfer distribution. Specifically, we estimate these specifications using quantile regression with the Epanechnikov kernel and the Hall et al. (1991) bandwidth selection. We report $95 \%$ confidence bands (i.e., the shaded areas in Figure 6).

[Figure 6 Here] 
The left panels show the fiscal offset parameters for the common shock while the right panels show the offset parameters for the county-specific shock. The upper panel focuses on private wages while the lower panel considers public wages. For reference, the fully-pooled benchmark results are indicated by the horizontal line with $95 \%$ confidence intervals. The point estimates at each quantile of the size-distribution (per capita) are indicated by the dots with red-shaded bands providing the $95 \%$ confidence intervals.

The key takeaway from this analysis is that it is not possible to reject the hypothesis that the pooled estimates are valid across the entire distribution, stratified by per capita transfer levels. This can be gleaned by looking for instances in which the two confidence intervals overlap. The only case in which they do not is in panel D and, even there, it is isolated to the lowest percentile of the distribution.

\section{Conclusion}

As Oh and Reis (2012) have correctly pointed out, much of the ARRA stimulus came in the form of transfers rather than increases in government consumption. This paper studies the role of the discretionary part of the stimulus in terms of mitigating wage income variance across counties, finding evidence of a particularly strong fiscal offset of the asymmetric county-level responses to the common shock to private wages and to the county-specific components of public wages.

It is important to note that the shocks to income after the stimulus bill is passed and funds are disbursed are jointly determined by contemporaneous, endogenous, responses to the actual disbursements, future shocks impinging on county-level wages, and the natural mean reversion of county-level wage income toward its long-run trend. Attempting to deal with the simultaneity of private and public expenditures arising from transfers at the county level is a more daunting task and worthy of further investigation. Our linkage of transfers to wage income shocks during the contract phase represents a first step in that direction.

Future work should aim at establishing a structural framework that can account for these collinear, asymmetric-sized wage income movements. Doing so may suggest both an improve- 
ment in the design of social insurance programs such as the unemployment insurance program and also a more efficient allocation of discretionary funds such as the ARRA. The fact that the policy function explains a small fraction of the observed cross-county variation in the ARRA suggests that following the protocol of the empirical model developed here in the future could bring about significant policy efficiency gains and thus more successes in helping counties most affected by recessions as emphasized in the ARRA's statement of objectives.

By the same token, it seems problematic to rely on models with a single representative agent to guide the discussion of fiscal multipliers when redistributive effects of asymmetric allocations inevitably arises. With asymmetric business cycles and incomplete markets, the fiscal multipliers and optimal policies will look very different.

Much remains to be done.

Acknowledgement The authors thank seminar participants at the College of William and Mary, Federal Reserve Bank of Richmond, Miami University, Oberlin College, Vanderbilt University, University of Cincinnati, and conference attendees at the Midwest Macroeconomics Meetings.

\section{References}

Asdrubali, Pierfederico, Bent Sorensen, and Oved Yosha, "Channels of Interstate Risk Sharing: United States 1963-1990," The Quarterly Journal of Economics, 1996, 111 (4), 10811110 .

Baxter, Marianne and Mario J. Crucini, "Business Cycles and the Asset Structure of Foreign Trade," International Economic Review, 1995, 36 (4), 821-54.

Bohn, Henning, "'The American Recovery and Reinvestment Act: Solely a government jobs program?" - Comment," Journal of Monetary Economics, 2013, 60 (5), 550-553.

Boone, Christopher, Arindrajit Dube, and Ethan Kaplan, "The Political Economy of Discretionary Spending : Evidence from the American Recovery and Reinvestment Act," Brookings Papers on Economic Activity, 2014, (Spring 2014), 375-428.

Chodorow-Reich, Gabriel, Laura Feiveson, Zachary Liscow, and William Gui Woolston, "Does State Fiscal Relief During Recessions Increase Employment? Evidence from the 
American Recovery and Reinvestment Act," American Economic Journal: Economic Policy, 2012, 4 (3), 118-45.

Cogan, John F and John B Taylor, "What the Government Purchases Multiplier Actually Multiplied in the 2009 Stimulus Package," Working Paper 16505, National Bureau of Economic Research October 2010.

Conley, Timothy G. and Bill Dupor, "The American Recovery and Reinvestment Act: Solely a government jobs program?," Journal of Monetary Economics, 2013, 60 (5), 535-549.

Dupor, Bill, Marios Karabarbounis, Marianna Kudlyak, and M. Saif Mehkari, "Regional Consumption Responses and the Aggregate Fiscal Multiplier," St Louis' Fed Working Paper, 2018, 1, 1-61.

Dupor, William, "The 2009 Recovery Act Directly Created and Saved Jobs Were Primarily in Government," Federal Reserve Bank of St. Louis Review, 2014, 2, 123-146.

Feyrer, James and Bruce Sacerdote, "Did the Stimulus Stimulate? Real Time Estimates of the Effects of the American Recovery and Reinvestment Act," NBER Working Paper Series, 2011, p. 16759.

Gimpel, James G., Frances E. Lee, and Rebecca U. Thorpe, "Geographic Distribution of the Federal Stimulus of 2009," Political Science Quarterly, 2012, 127 (4), 567-595.

Goodman, Christopher J. and Steven M. Mance, "Employment loss and the 2007-09 recession: an overview," Monthly Labor Review, 2011, (April), 3-12.

Hall, Peter, Simon J. Sheather, M. C. Jones, and J. S. Marron, "On Optimal DataBased Bandwidth Selection in Kernel Density Estimation," Biometrika, 1991, 78 (2), 263-269.

Inman, Robert P, "States in Fiscal Distress," Working Paper 16086, National Bureau of Economic Research June 2010.

Johnson, N., "Does the American Recovery and Reinvestment Act Meet Local Needs?," State and Local Government Review, 2009, 41 (2), 123-127.

Leduc, Sylvain and Daniel Wilson, "Are State Governments Roadblocks to Federal Stimulus? Evidence on the Flypaper Effect of Highway Grants in the 2009 Recovery Act," American Economic Journal: Economic Policy, 2017, 9 (2), 253-92.

Nakamura, Emi and Jón Steinsson, "Fiscal Stimulus in a Monetary Union: Evidence from US Regions," American Economic Review, 2014, 104 (3), 753-792.

Oh, Hyunseung and Ricardo Reis, "Targeted transfers and the fiscal response to the great recession," Journal of Monetary Economics, 2012, 59 (Supplement), S50 - S64.

Perri, Fabrizio and Vincenzo Quadrini, "International Recessions," American Economic Review, April 2018, 108 (4-5), 935-84.

Wilson, Daniel J., "Fiscal Spending Jobs Multipliers: Evidence from the 2009 American Recovery and Reinvestment Act," American Economic Journal: Economic Policy, 2012, 4 (3), 250-282. 
Table 1: Cumulative ARRA Revenue and Expenditures

\begin{tabular}{lr}
\hline \hline Item & Billion \$ \\
\hline Tax Revenues & -95 \\
Individual taxes (1) and (2) & -20 \\
Corporate taxes (3) & $\mathbf{- 1 1 5}$
\end{tabular}

\section{Expenditures}

Current transfer payments $\quad 516$

$\begin{array}{ll}\text { Capital transfer payments } & 79\end{array}$

Consumption expenditures 43

$\begin{array}{ll}\text { Subsidies (4) } & 18\end{array}$

Gross investment 17

Total expenditures $\quad 672$

$\begin{array}{ll}\text { Net borrowing (in addition to deficit) } & 787\end{array}$

Current transfers to persons

Refundable tax credits (5) 149

Unemployment programs $\quad 59$

SNAP 39

Student financial assistance 17

One-time $\$ 250$ payments (6) 14

Other programs (7)

$\begin{array}{ll}\text { Total current transfers to persons } & 281\end{array}$

Grants-in-aid to state and local governments (8)

$\begin{array}{ll}\text { Medicaid } & 95\end{array}$

$\begin{array}{ll}\text { Education } & 76\end{array}$

Other (9) 63

Total other current transfers $\quad 234$

Capital transfer payments

Capital grants (10) 50

Capital transfers to business (11) 29

Total capital transfer payments $\quad 79$

Note: 1) Includes reductions to tax with-holdings associated with the Making Work Pay refundable tax credit; 2) Includes an increase to the individual AMT exemption amount and business tax incentives claimed by individuals; 3) Includes special allowances for certain property acquired during 2009 and other business tax incentives; 4) Includes funding to supplement Section 8 housing subsidies and to promote the use of efficient and renewable energy; 5) Includes outlays and offsets to tax liabilities associated with the Making Work Pay, American Opportunity, and other refundable tax credits as well as an expansion of the earned income and child tax credits; 6) Payments to recipients of Social Security, Supplemental Security Income, veterans' benefits, and railroad retirement benefits; 7) Includes funding for COBRA premium assistance payments and veterans' benefits, and payments to cover digital converter box redemptions; 8) Excludes $\$ 675$ million grants to fund Making Work Pay tax credits in the territories; 9) Includes grants to fund programs related to national defense, public safety, economic affairs, housing and community services, income security, and unemployment; 10) Includes grants for highway and public transit infrastructure construction and restoration; 11) Includes homebuyer tax credits and grants for specified energy properties. 
Table 2: Estimated Parameters of Wage Income Processes

\begin{tabular}{lccccc}
\hline \hline \multicolumn{5}{c}{ Panel A: Persistence $\rho_{i}$} \\
\hline & Mean & Std. dev. & $\mathrm{p} 25$ & $\mathrm{p} 50$ & $\mathrm{p} 75$ \\
\hline Total wages & 0.73 & 0.17 & 0.66 & 0.77 & 0.84 \\
Private wages & 0.75 & 0.17 & 0.68 & 0.79 & 0.87 \\
Public wages & 0.71 & 0.20 & 0.60 & 0.76 & 0.86 \\
\hline
\end{tabular}

Panel B: Factor Loading on Common Shock $\lambda_{i}$

\begin{tabular}{lccccc}
\hline & Mean & Std. dev. & p25 & p50 & p75 \\
\hline Total wages & 0.99 & 0.59 & 0.60 & 1.01 & 1.35 \\
Private wages & 0.99 & 0.68 & 0.59 & 1.02 & 1.35 \\
Public wages & 0.94 & 0.83 & 0.45 & 0.81 & 1.27 \\
\hline
\end{tabular}

Panel C: Std. Dev. of the County-specific Shock $\sigma_{i}(\%)$

\begin{tabular}{lccccc}
\hline & Mean & Std. dev. & p25 & p50 & p75 \\
\hline Total wages & 4.02 & 3.84 & 2.22 & 2.97 & 4.21 \\
Private wages & 5.49 & 6.59 & 2.56 & 3.54 & 5.42 \\
Public wages & 4.72 & 3.94 & 2.49 & 3.52 & 5.32 \\
\hline \hline
\end{tabular}

Note: The statistical appendix shows cross-county kernel densities of each estimated parameter. 
Table 3: Benchmark Fiscal Policy Estimation

\begin{tabular}{|c|c|c|c|c|}
\hline & \multicolumn{4}{|c|}{ Panel A: Aggregate Wage } \\
\hline & (1) & $(2)$ & $(3)$ & $(4)$ \\
\hline Composite Shocks & $\begin{array}{c}-0.103^{* * *} \\
(0.027)\end{array}$ & & & \\
\hline Macro Shocks & & $\begin{array}{c}-0.137^{* * *} \\
(0.035)\end{array}$ & & $\begin{array}{c}-0.131^{* * *} \\
(0.042)\end{array}$ \\
\hline Micro Shocks & & & $\begin{array}{c}-0.085^{* * *} \\
(0.023)\end{array}$ & $\begin{array}{c}-0.073^{* * *} \\
(0.024)\end{array}$ \\
\hline Observation & 3,133 & 3,133 & 3,133 & 3,133 \\
\hline Adj-R-Sqr & 0.010 & 0.018 & 0.007 & 0.023 \\
\hline
\end{tabular}

Panel B: Private Wage

$(1)$

(2)

(3)

\begin{tabular}{lcccc}
\hline Composite Shocks & -0.020 & & & \\
& $(0.019)$ & & & \\
Macro Shocks & & $-0.069^{* * *}$ & & $-0.069^{* *}$ \\
& & $(0.024)$ & & $(0.028)$ \\
Micro Shocks & & & -0.006 & 0.003 \\
& & & $(0.021)$ & $(0.020)$ \\
\hline Observation & 3,133 & 3,133 & 3,133 & 3,133 \\
Adj-R-Sqr & 0.000 & 0.004 & -0.000 & 0.004 \\
\hline
\end{tabular}

Panel C: Public Wage

\begin{tabular}{|c|c|c|c|c|}
\hline & (1) & $(2)$ & (3) & (4) \\
\hline Composite Shocks & $\begin{array}{c}-0.125^{* * *} \\
(0.032)\end{array}$ & & & \\
\hline Macro Shocks & & $\begin{array}{c}0.017 \\
(0.045)\end{array}$ & & $\begin{array}{c}0.029 \\
(0.048)\end{array}$ \\
\hline Micro Shocks & & & $\begin{array}{c}-0.131^{* * *} \\
(0.033) \\
\end{array}$ & $\begin{array}{c}-0.134^{* * *} \\
(0.026) \\
\end{array}$ \\
\hline Observation & 3,133 & 3,133 & 3,133 & 3,133 \\
\hline Adj-R-Sqr & 0.015 & -0.000 & 0.017 & 0.017 \\
\hline
\end{tabular}

Standardized beta coefficients; standard errors in parentheses

${ }^{*} p<0.10,{ }^{* *} p<0.05,{ }^{* * *} p<0.01$

Note: The estimated equation in columns (4) is $T_{i, L}=\alpha+\beta_{M}\left(\lambda_{i} \varepsilon_{L-1}\right)+\beta_{m} \varepsilon_{i, L-1}+\nu_{i}$ where $\lambda_{i} \varepsilon_{L-1}$ is the estimated impact of the common shock on county $i$ during the Great Recession and $\varepsilon_{i, L-1}$ is the cumulative effects of the county-specific shock (both estimated residuals from estimating income processes (Table 2)) during the Great Recession. Specifications (2) and (3) consider each shock exclusively, while specifications (1) restrict the policy response to be symmetric across the common and county-level shocks. All specifications are estimated using OLS regressions with bootstrapped standard errors to account for the use of generated regressors. 
Table 4: Fiscal Offset Estimates: Pooling Sectors

\begin{tabular}{lccc}
\hline \hline & \multicolumn{3}{c}{ Dependent Variable: ARRA Transfers } \\
\cline { 2 - 4 } & $(1)$ & $(2)$ & $(3)$ \\
\hline Macro Shocks (Private) & $-0.070^{* * *}$ & $-0.068^{* *}$ & \\
& $(0.026)$ & $(0.030)$ & \\
Micro Shocks (Private) & 0.004 & & -0.005 \\
& $(0.037)$ & & $(0.036)$ \\
Macro Shocks (Public) & $0.025^{*}$ & 0.013 & \\
& $(0.015)$ & $(0.016)$ & \\
Micro Shocks (Public) & $-0.135^{* * *}$ & & $-0.131^{* * *}$ \\
& $(0.029)$ & & $(0.023)$ \\
\hline Observation & 3,133 & 3,133 & 3,133 \\
Adj-R-Sqr & 0.022 & 0.004 & 0.017 \\
\hline \hline
\end{tabular}

Standardized beta coefficients; Standard errors in parentheses

${ }^{*} p<0.10,{ }^{* *} p<0.05,{ }^{* * *} p<0.01$

Note: All specifications are estimated using OLS regressions with bootstrapped standard errors. The regression estimated in specification (1) is $T_{i, L}=\alpha+\beta_{M}^{\text {Private }}\left(\lambda_{i} \varepsilon_{L-1}\right)+\beta_{m}^{\text {Private }} \varepsilon_{i, L-1}+$ $\beta_{M}^{\text {Public }}\left(\lambda_{i} \varepsilon_{L-1}\right)+\beta_{m}^{\text {Public }} \varepsilon_{i, L-1}+\nu_{i}$. 
Figure 1: ARRA Transfers per Capita

(a) Quarterly flow of funds received by counties

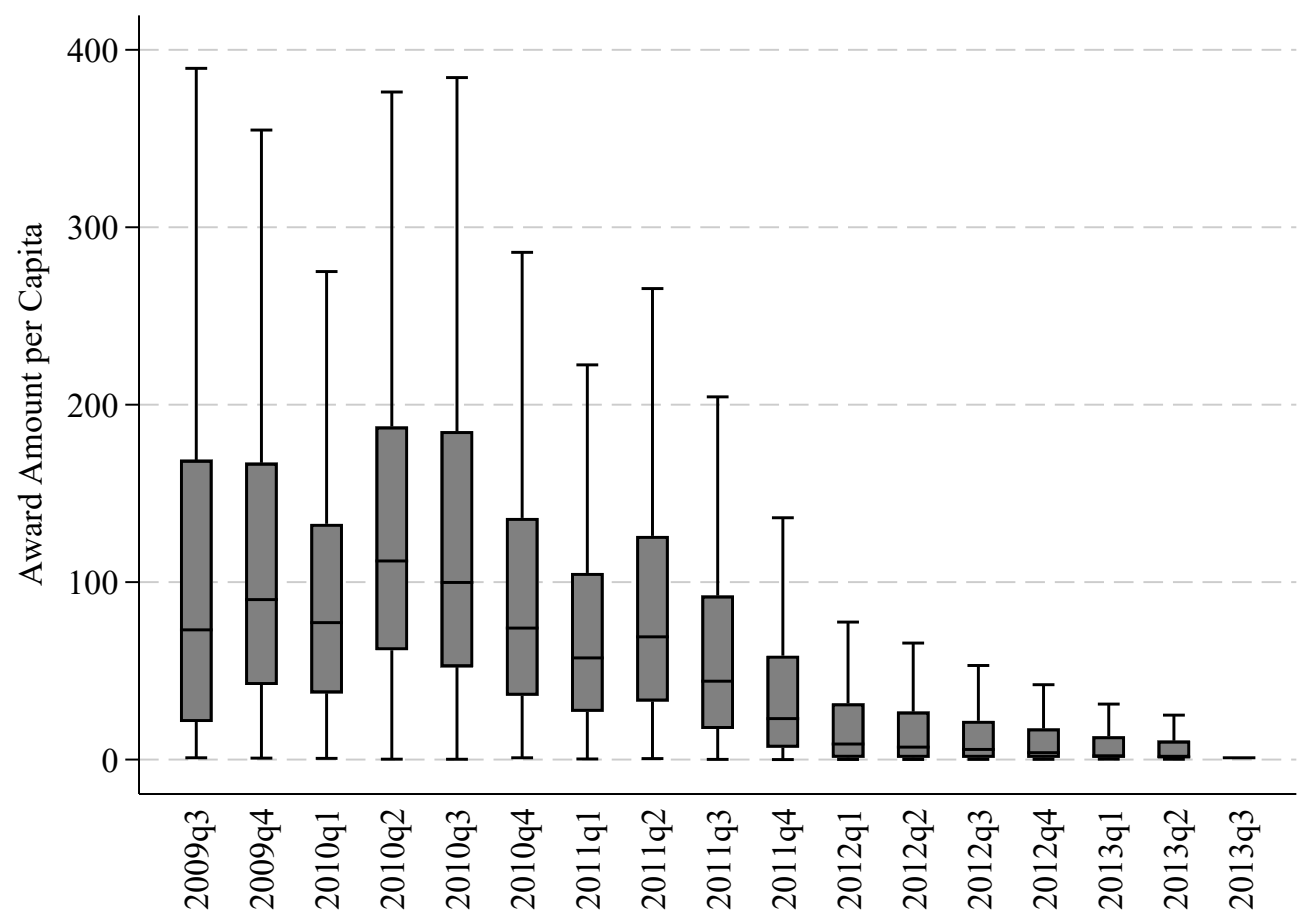

(b) Cumulative flow of fund received by counties

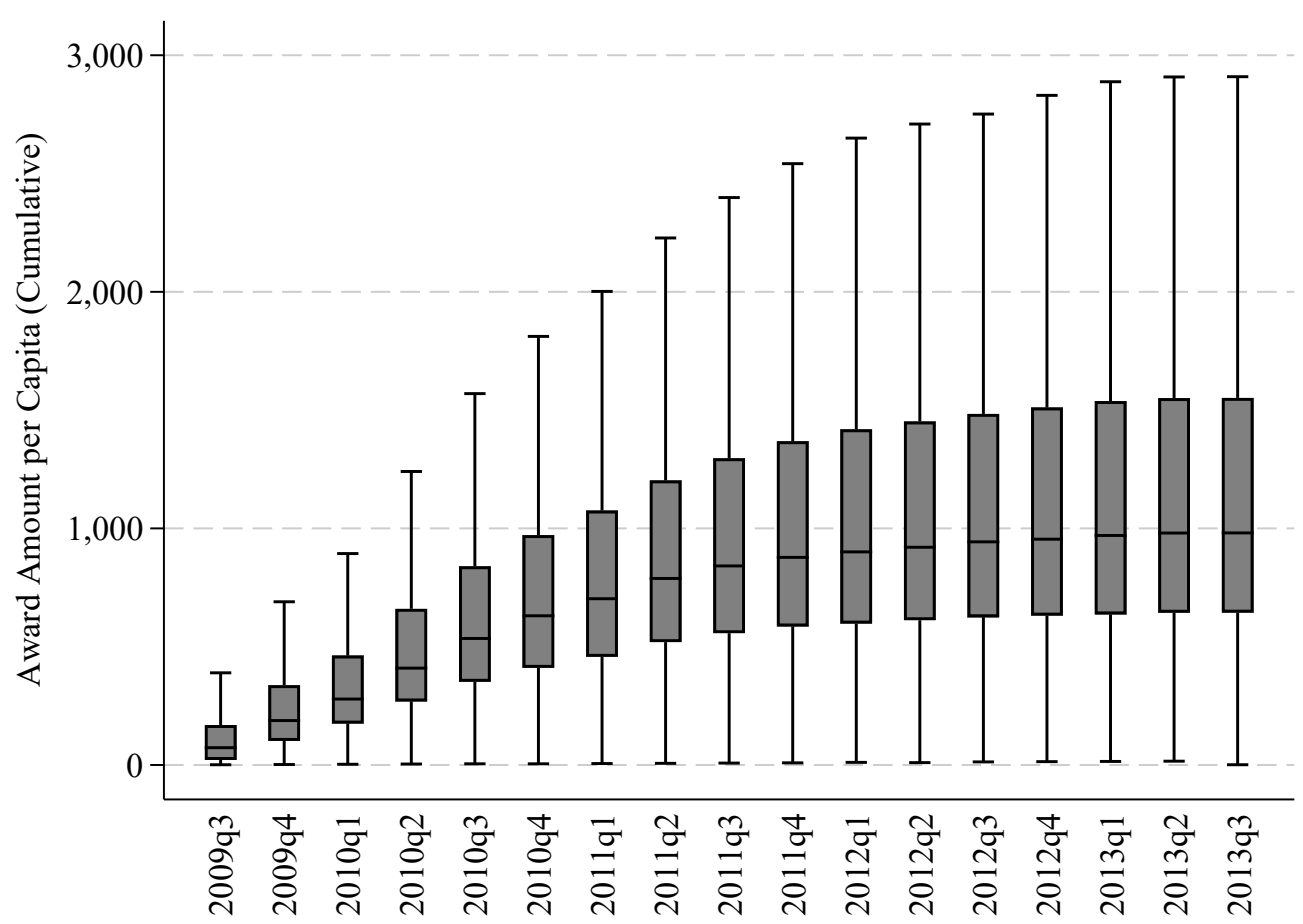

Note: These figures are box and whisker plots of the cross-sectional distribution of transfers to counties in each quarter: the maximum, minimum, $25^{\text {th }}$ and $75^{\text {th }}$ percentiles (shaded bars) and the medians (horizontal line within each bar). The upper figure is the transfers per capita county, while the lower figure is the corresponding cumulative amount. 
Figure 2: Geography of Economic Contraction and ARRA Transfers

(a) Cumulative Peak-to-Trough Great Recession Wage Income Shocks

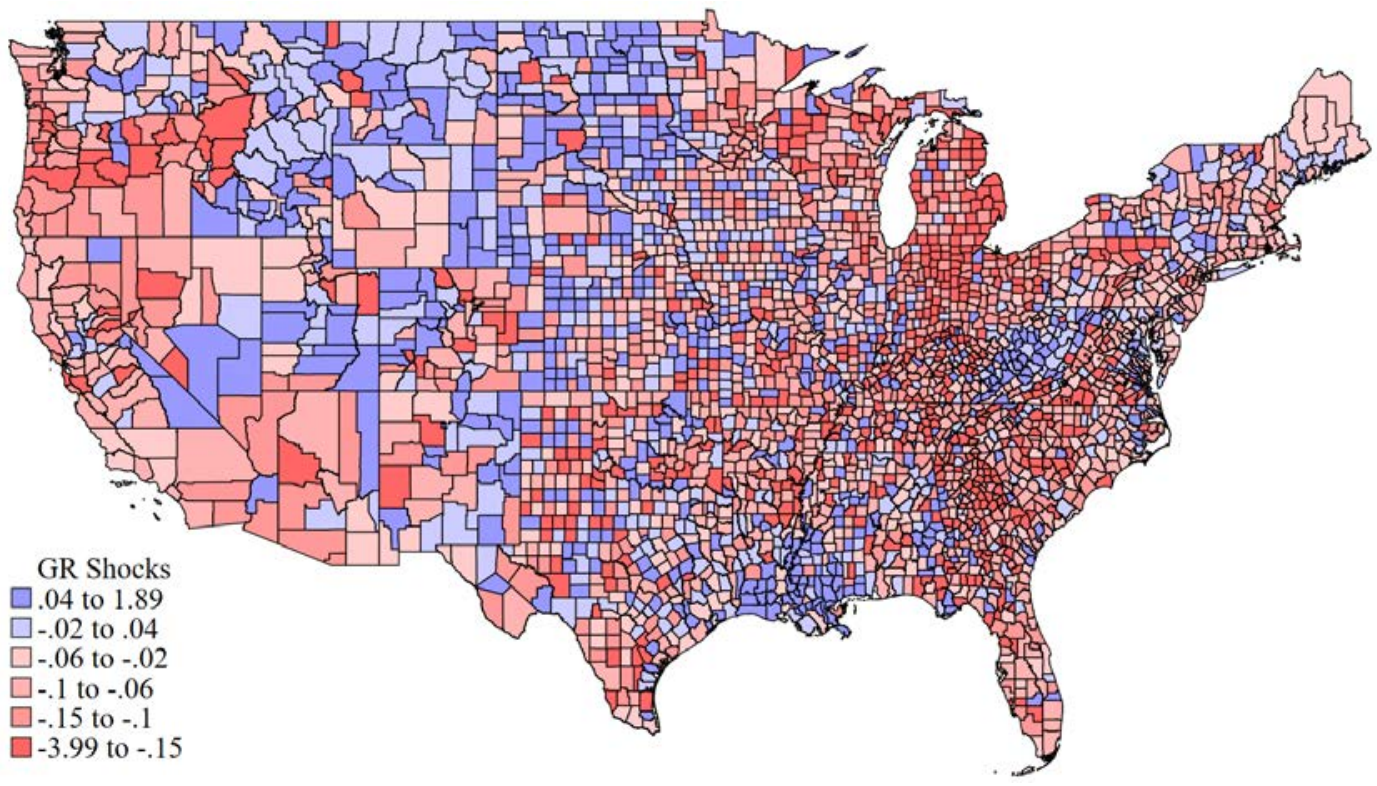

(b) Cumulative Transfers as Fractions of Income

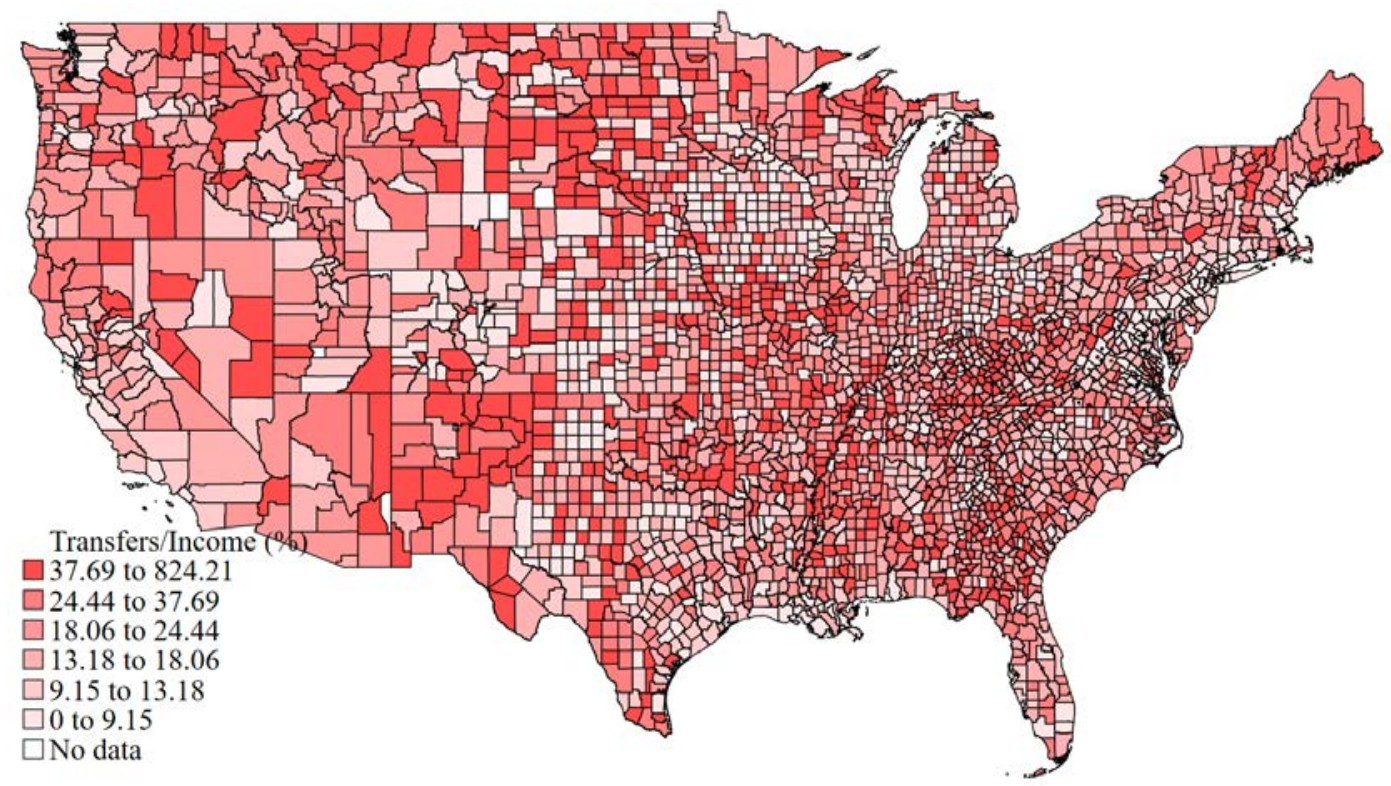

Note: The upper panel plots cumulative Great Recession shocks from the official peak and the official trough of the Great Recession. Map data are from the U.S. Census (2010 Map). We use official NBER cycles for peaks and troughs. The lower figure plots the level of transfers per capita divided by income. Locations denoted with "no data" include ones no data reported. 
Figure 3: Cumulative Shocks Distribution during the Great Recession
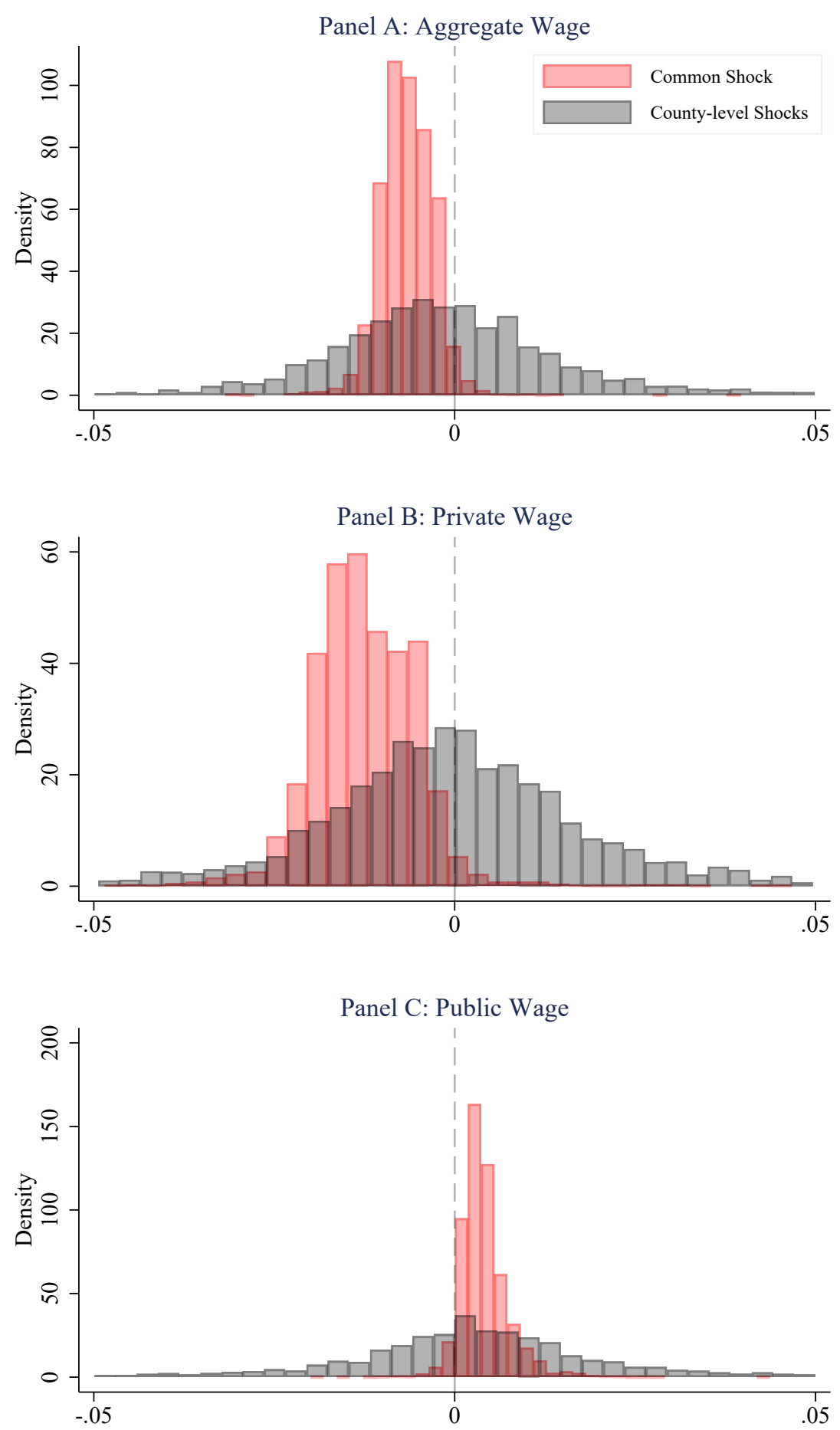

Note: This figure plots the distribution of the cumulative wage income shocks over the official NBER Great Recession quarters (2007:Q4 to 2009:Q2). Panels A, B, and C present the distributions for the aggregate, private, and public wage incomes, respectively. In each panel, we show the histograms for the common shocks $\left(\lambda_{i} \varepsilon_{t}\right)$ and the county-level shocks $\left(\varepsilon_{i, t}\right)$. 
Figure 4: Great Recession Shocks and ARRA Transfers

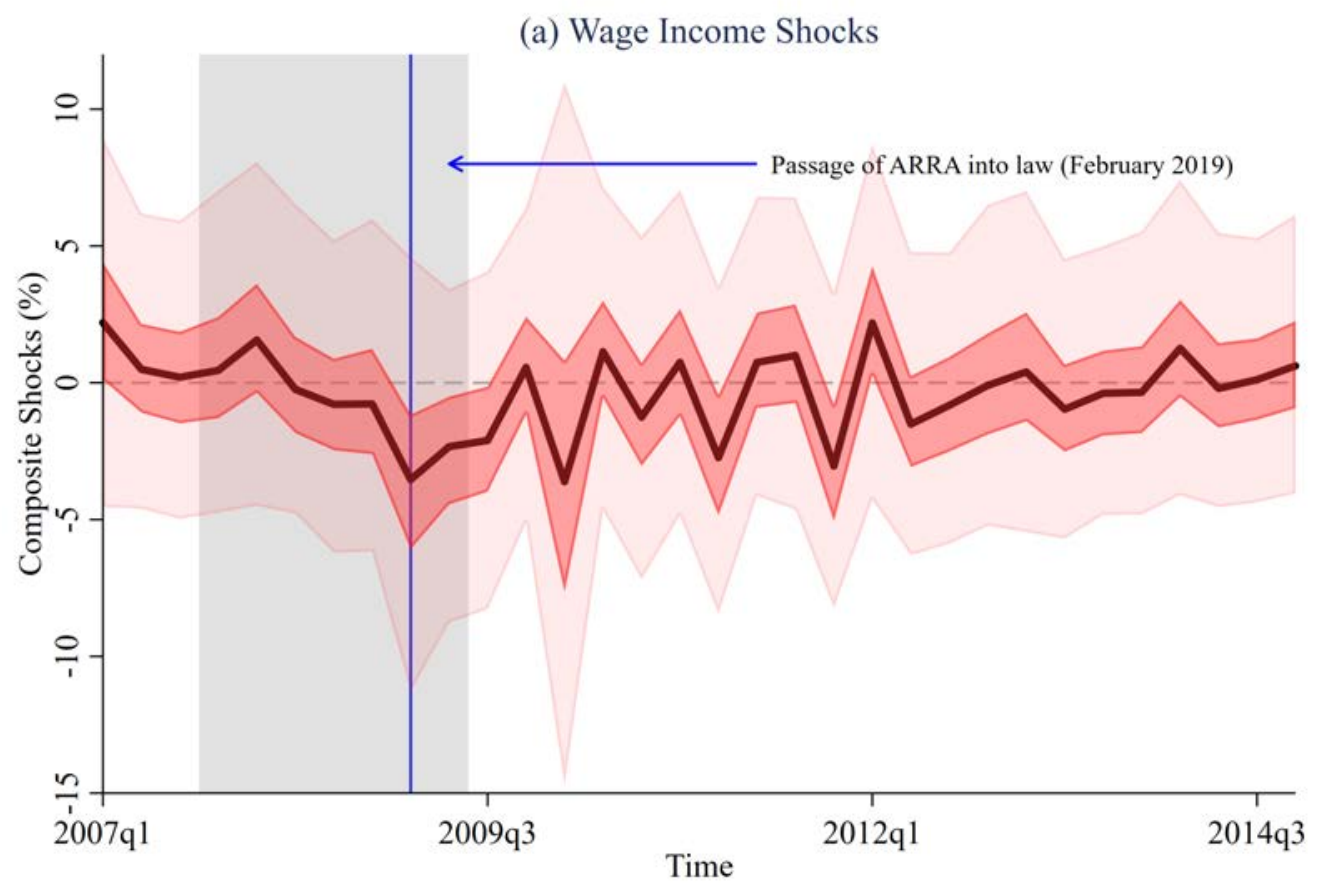

(b) ARRA Flow as Fraction of Income (\%)

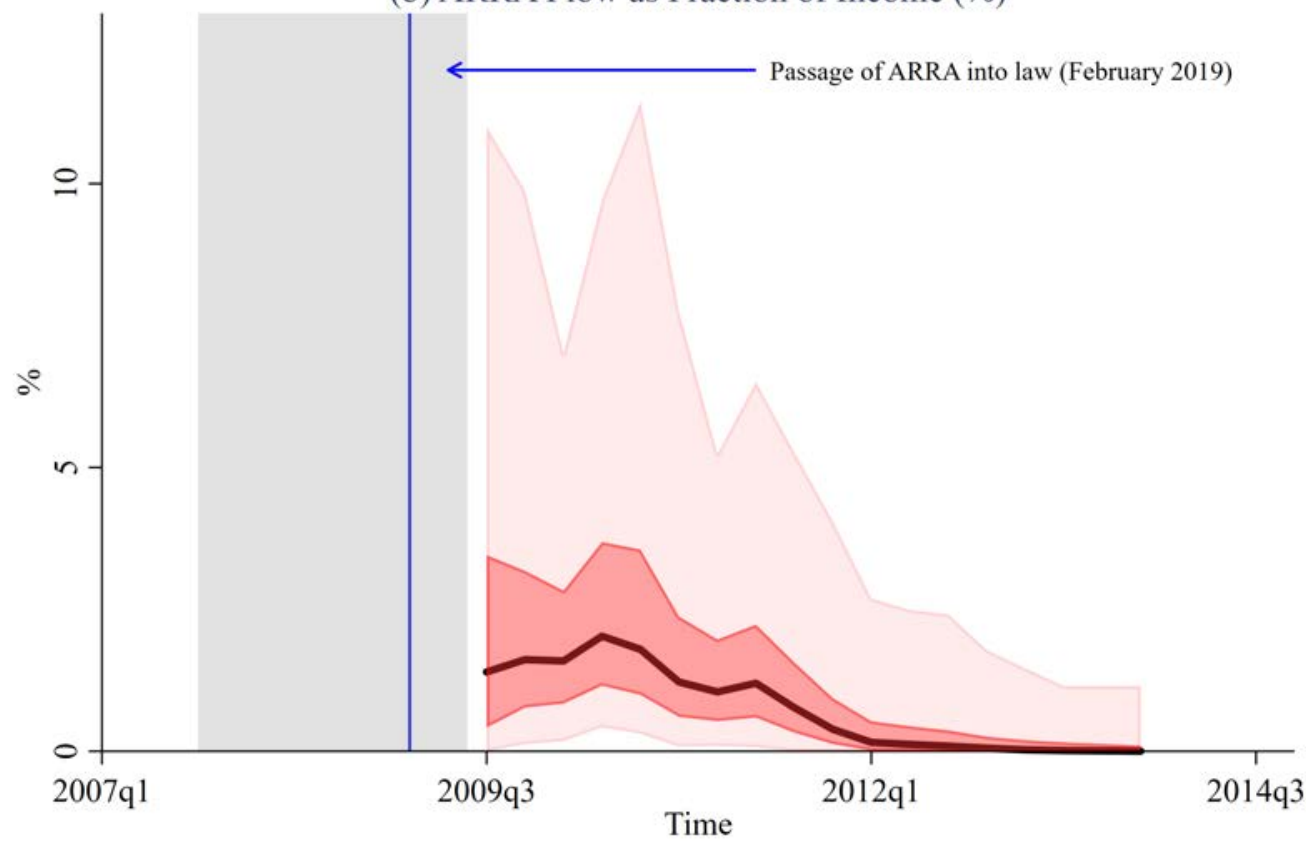

Note: This figure plots the distributions of the composite wage income shocks (panel a) and of the ARRA flow as a fraction of income (panel b, in \%). The solid line denotes the median across counties. The darker shaded areas denote the interquartile ranges while the lighter shaded areas denote the $5^{\text {th }}$-to- $95^{\text {th }}$-percentile range. 
Figure 5: Sensitivity Analysis: Dropping County One by One
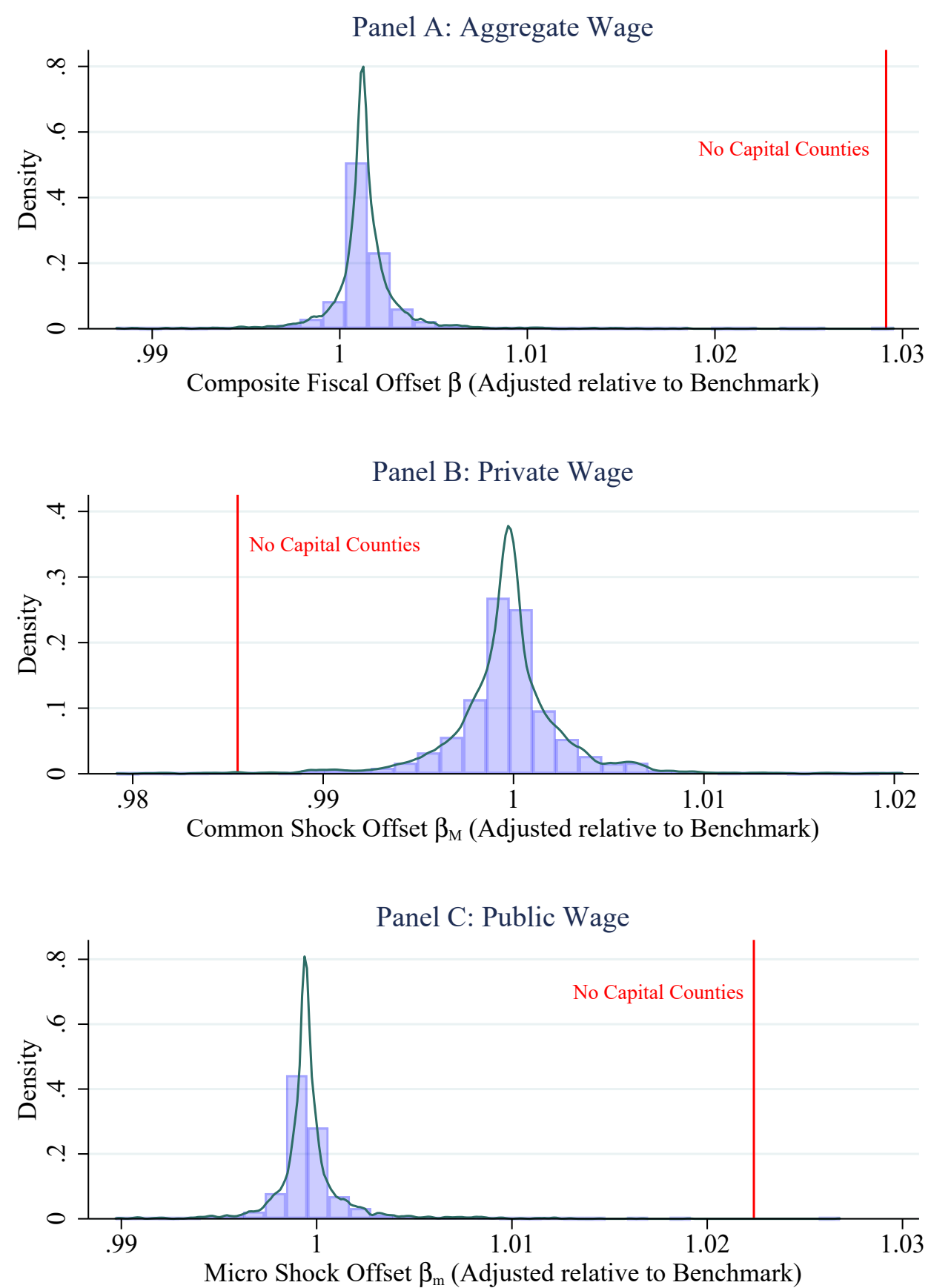

Note: We regenerate the baseline fiscal offset result, leaving one county out at a time, and plot the corresponding distribution of the composite offsets $\beta$ for aggregate wage, the macro common offsets $\beta_{M}$ for private wage, and the micro common offsets $\beta_{m}$ for public wage across these "leave-onecounty-out" samples in Figure 5, adjusted by the corresponding estimates as in Table 3. The red lines denote the estimates without counties with a state capital. 


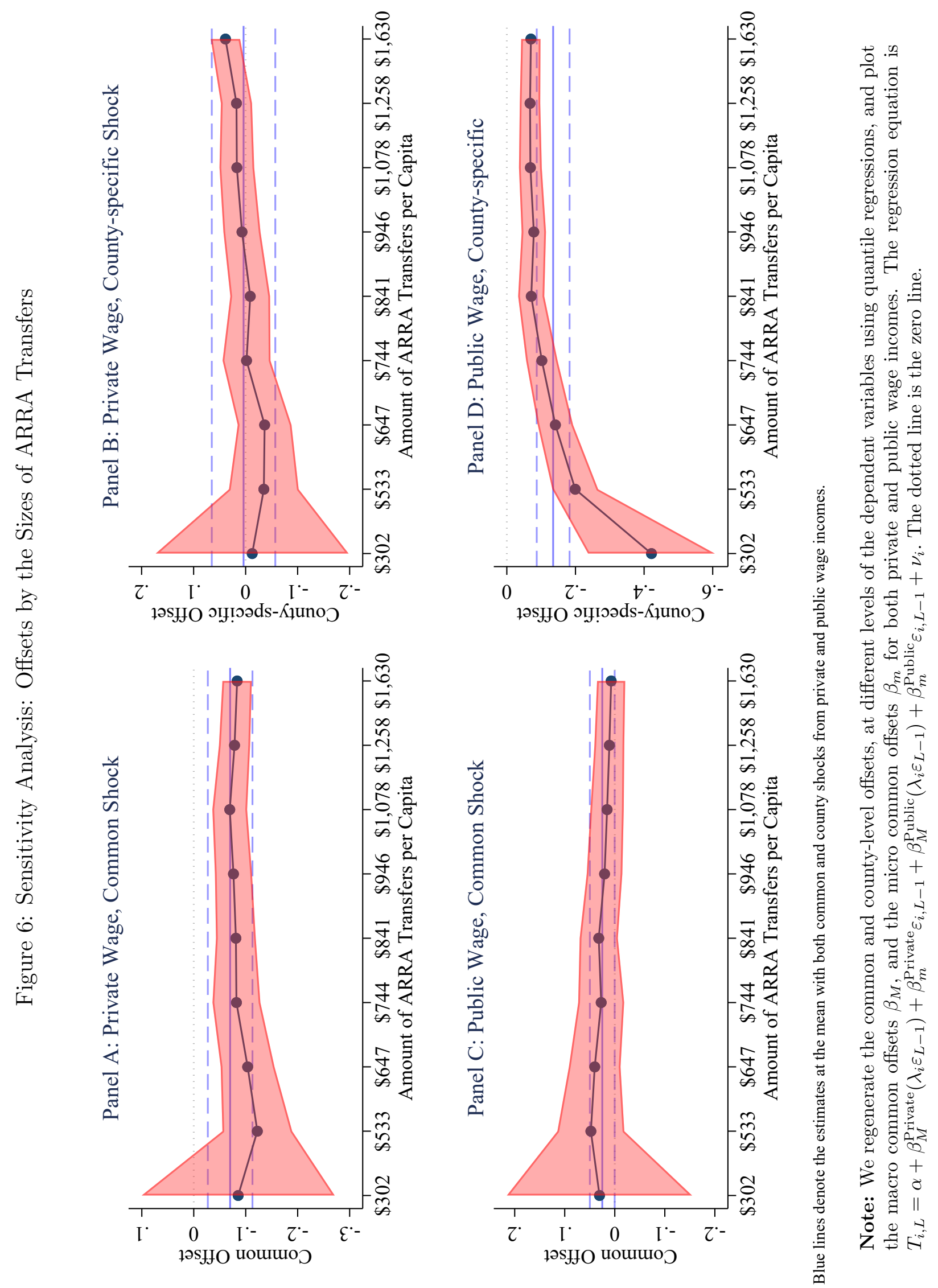




\section{APPENDIX NOT INTENDED FOR PUBLICATION}

\section{A Appendix: Wage Income Data}

\section{A.1 Wage Income Data}

The Quarterly Census of Employment and Wages (QCEW) is the tabulation of employment and wages of establishments, which report to the Unemployment Insurance (UI) programs of the United States. Employment covered by these UI programs represents about $97 \%$ of all civilian employees that receive wages or salaries in the county. The lowest level of spatial aggregation available is what we use, the (county-level) Area-FIPS codes (by the Geography Division of the U.S. census).

The $Q C E W$ reports four different wage income measures: total quarterly wages, taxable quarterly wages, average weekly wages, and quarterly contributions. We use total quarterly wages, which according to the U.S. Bureau of Labor Statistics,

"Wages include bonuses, stock options, severance pay, profit distributions, cash value of meals and lodging, tips and other gratuities, and, in some States, employer contributions to certain deferred compensation plans such as 401(k) plans. Covered employers in most States report total compensation paid during the calendar quarter, regardless of when the services were performed. A few State laws, however, specify that wages be reported for or based on the period during which services are performed rather than the period during which compensation is paid."

Data Transformations The nominal wage income is deflated by the GDP deflator series GDPDEF (which is the implicit price deflator used to deflate nominal GDP), retrieved from the St. Louis' FRED. In the empirical applications, they are also normalized by the county labor force. The wage income data are seasonally adjusted at the quarterly frequency. We also find that using population size, as opposed to the labor force, has little effects on our estimates of fiscal offset.

Matching Wage Income Data to ARRA Data at the County Level Since the QCEW data are aggregated to the county level (as designated by the area county-level FIPS codes) whereas the ARRA data are by zip-code, we aggregate the ARRA data to the county level using Census data files that allocate zip codes to county-level FIPS codes. Details of the constructions of ARRA flow data are included in this appendix. 


\section{B Appendix: Construction of ARRA Flow}

The data on ARRA flow were constructed from 18 separate datasets, each of which contains information taken from reports filed by ARRA grant recipient as required by section 1512 of the American Recovery and Reinvestment Act of 2009 and as outlined by memorandum M-09-21. Each of these datasets contains information on the filings from a single quarter. The first period for which records are available is the third quarter of 2009, and the last data set provided by Recovery.gov is for the third quarter of 2013.

\section{B.1 Raw Data}

The raw data originally obtained from Recovery.gov contain 96 variables, but for the purpose of constructing a flow variable for each location, only a small subset of these variables is necessary. The items needed to construct a flow with this dataset are a locator that uniquely identifies the award or sub-award, an indicator of the recipient role, a dollar amount indicating award payments, and one or more variables that indicate the location of the disbursements. This section shall detail the rationale for our choices of variables used in the construction of the ARRA flow.

\section{B.1.1 Structure of the Data: Recipients}

The dataset is hierarchical with observations at the level of prime recipient, sub-recipient, and vendor. Grants are awarded by federal agencies to prime recipients who record their own expenditure as it progresses, but prime recipients may further delegate funds to sub-recipients who also record their expenditure or have the prime recipient record their expenditure on their behalf. There is a further level of recordings representing expenditures on vendors greater than $\$ 25,000$. For the purposes of developing a location-specific flow, these vendor observations are intractable due to their lack of unique identifiers. Because most measures of expenditure for the prime recipient include that expenditure carried out by the sub-recipient, sub-recipient records need to be treated in a way that is fundamentally different from prime recipient records; the recipient role variable is essential in order to maintain the dataset's hierarchy and avoid double counting.

\section{B.1.2 Award Identifiers}

The award key and the sub-award number are used to identify the awards across time. The award key is a better identifier than the award number due to a few fundamental flaws in the award numbers construction. 


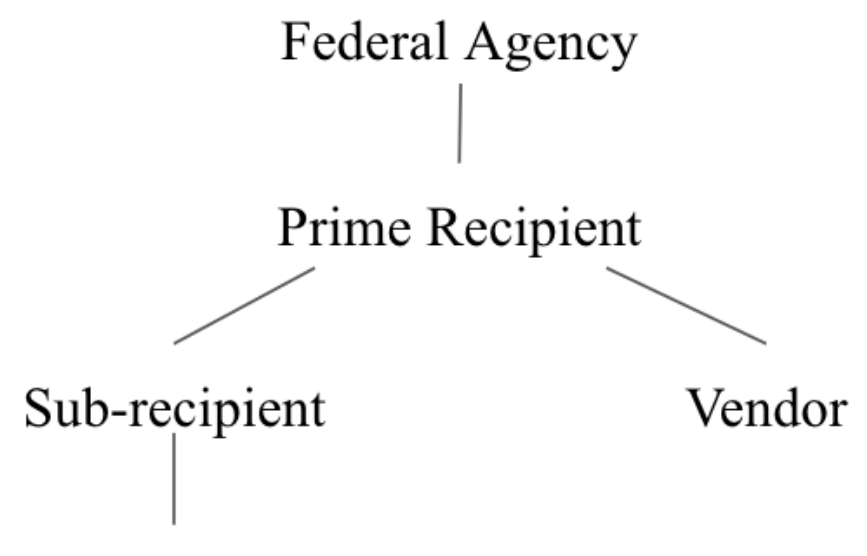

Vendor

1. Award numbers were assigned by the awarding or funding agency, but each agency has a different methodology for creating award numbers. This results in several thousand cases where award keys that are the same despite their refer to entirely separate grants.

2. Award numbers that refer to the same project change over time when the agency in charge of award administration is changed.

3. The award numbers are often highly complex (e.g. they are case sensitive and full of special character) and they often have recording errors as a result.

After the federal government aggregated the reporting data and discovered these issues, award keys were added to ease the identification of awards before dissemination of the data. Along with the award key, the sub-award numbers are used. The award key uniquely identifies the prime recipient grant, but a further piece of information is required to identify sub-recipient grants. Here, the sub-award number in conjunction with the award key uniquely identifies the sub-recipient. The same ambiguity does not attend the use of the sub-award number as does the award number because, by nature of the hierarchy, all sub-awards corresponding to each award key are assigned sub-award numbers by the same agency.

\section{B.2 Measures of Expenditure}

There are several different measures of dollar amounts that could be used to create a flow, but the most valid and useful is total federal ARRA expenditure, which we shall refer to as expenditure. 
This measure is the cumulative flow of expenditure to the awardee up to the quarter in question, but due to the hierarchy of awards and to associate expenditure with locations, it is necessary to treat this expenditure measure slightly differently for prime and sub-awardees. ${ }^{15}$

\section{B.3 Data Correction}

The first step gone through in correcting the data was removing the duplicate values. There are a very small number of instances where the award key for the prime recipient is recorded more than once in the same period. This occurs only in 114 of over a million observations. These are generally due to small errors in the reporting of the award number leading to duplicated reports. In these cases, the observation with the lower row number is taken. The same procedure is carried out on the sub-awards which have a similarly small number of duplicated dates, award key, sub-award number combinations.

Only one observation was conclusively found to have expenditure misreported. This is the 2013:Q1 observation of award key 102,760 (row 4,262,984). Here, expenditure values should be recorded as 5 million rather than 5 billion. To account for such misreporting, we remove per capita transfers that are larger than the $99^{\text {th }}$ percentile of observations. It seems likely that there are other far smaller errors in the data but these prove very difficult to conclusively identify. One issue of misreporting that may be correctable in the future but was not carried out here was those cases in which toward the end of the recording period, expenditure is set at zero once the project is complete. These were not corrected here because it is difficult to impossible to systematically distinguish these errors from those cases where awards were revoked.

\section{B.4 Construction of exclusive expenditure}

Vendor transactions are not uniquely identifiable due to missing names, missing duns numbers, and cases of an awardee having a changing number of recorded transactions with the same vendor

15) Of the other possible choices that we considered, the award amount variable is insufficient because it only covers prime recipient amounts. Using this would leave something to be desired because it would not track the money well to where it ends up. After all, the location of sub-recipients may differ markedly from the location of prime recipients. The local amount variable is also flawed as an account of expenditure; this variable was constructed after the fact to aid in the identification of the final location of expenditure. It was calculated through subtracting the sub-award amounts and vendor expenditure of different locations from the prime award amount. Due to the focus on award amounts rather than money as it is used up over time, for the purposes of tracking spending the local amount is insufficient. More problematically, only those expenditures with a report in a given period are subtracted from the prime recipient award. Why this is an issue is best explained through an example. In the first recorded quarter, a university is awarded a one-million-dollar grant. During this quarter, they do not spend any money or engage in any sub-awards, so their local amount variable is one million. A few quarters later, after the university has expended the money on ongoing transactions with vendors in different states and sub-awardees in different counties, the local amount will be one million minus these vendors and sub-award amounts. Finally, in the last period, because these transactions with sub-recipients and vendors have come to completion, the dataset for that period does not contain a record of these transactions and the local amount for the university returns to one million. 
over time. This makes vendor transactions nearly impossible properly to track over time, so the first step in constructing a measure of expenditure that tracks the spending as close to its final location as possible is to remove all observations where the recipient role is vendor.

A new variable of expenditure ("exclusive expenditure") now needs to be constructed that is devoid of double counting. This variable captures expenditure of the awardee, excluding that expenditure which occurred in a different location. Exclusive expenditure for the prime recipient must be calculated as the sum of sub-recipient expenditures subtracted from the prime recipient expenditure for each period. The exclusive expenditure for the sub awardees is then just their expenditure as marked. In the case where the sum of sub-award amounts exceeds the prime award amount, the prime award amount is set to zero and the sub-award amounts are taken asis. Before this process can be carried out, because our expenditure variable is a cumulative flow, certain parts of the dataset need to be extended to fill those periods in which no expenditure report was filed.

Sometimes a record of grant expenditure for an awardee has gaps in time. Filling in these gaps can be done in a few ways, but to avoid spurious extrapolation, the method chosen here is to assume that the flow that occurred during the quarter in which the recipient failed to file a report is zero and set the cumulative expenditure amount of any period following a missing value equal to the closest expenditure amount before the gap. A similar issue occurs when an award is complete and the awardee permanently stops filing reports. In this case, a similar assumption of zero flow is made for further periods, and new rows are populated with new periods. Although it is not strictly necessary, we ensure that each uniquely identifiable prime and sub-award has a single observation of the cumulative expenditure in every period to minimize errors in the construction of the variable.

\section{B.5 Location Identifiers: Assigning FIPS Codes}

The dataset does not contain indicators of which county the expenditure occurred in, so county FIPS codes need to be extrapolated from other data on the location, namely the state, the zip code, and the city name. Grants that go to US territories and countries outside the US are removed.

The place of purpose postal code in the raw data identifies the location of the grant with a ZIP +4 code. Although these codes are extremely precise, identifying a location down to the city block, ZIP +4 codes are based on postal routes and change monthly. Additionally, data on $\mathrm{ZIP}+4$ codes is generally unavailable. For this reason, the far more stable five-digit ZIP code is derived from the $\mathrm{ZIP}+4$. To supplement this method of FIPS county code identification, the place of purpose city names are also used after cleaning. The reason these ZIP codes must be supplemented with additional information is that about a quarter of all ZIP codes cross county boundaries. Town and city names with their associated state cannot be used on their own 
because many cities and towns also overlap county boundaries.

Two data-sets were used to identify FIPS codes. A combination of HUD and Census data is used to identify which FIPS code(s) correspond to each ZIP code, and Census data is used to identify which FIPS code(s) correspond to each city and town name. After joining these two datasets with the expenditure data, a few steps can be taken to cut down on ambiguity. First, any observation with only a single FIPS code associated with its zip code or only a single FIPS code associated with its city name is assigned that FIPS code. Second, ambiguity can be further attenuated through taking those cases where both ZIP code and city name exhibit ambiguity and taking those instances where only one of the possible FIPS codes associated with the ZIP and city match. In this case, the matching FIPS code is assigned. Using both ZIP codes and city names cuts the incidence of having one or more possible counties from $26 \%$ to $6 \%$ of all observations.

This $6 \%$ of observations require that the expenditure be distributed in some fashion, but one further step can be made to increase the accuracy of this distribution. Through keeping only those FIPS codes where both the possible city FIPS and the possible ZIP-FIPS match each other, the number of possible choices can often be down substantially. With the remaining possible county codes, the expenditure amounts are split amongst the counties in proportion with each possible county's population.

\section{B.6 Finishing Up}

Retrieving each county's expenditure requires summing up the distributed exclusive expenditure values associated with each county FIPS code in each period. To derive the flow, take the first difference of these values. It is important to note that because data reporting started in Q3

of 2009 but actual disbursements of ARRA expenditure started earlier in the second quarter of 2009. This flow variable is then transformed into per capita real terms in the same fashion as the wage income variable.

\section{Appendix: Additional Tables and Figures}


Figure C.2: Kernel densities of key estimated parameters - Aggregate Wage
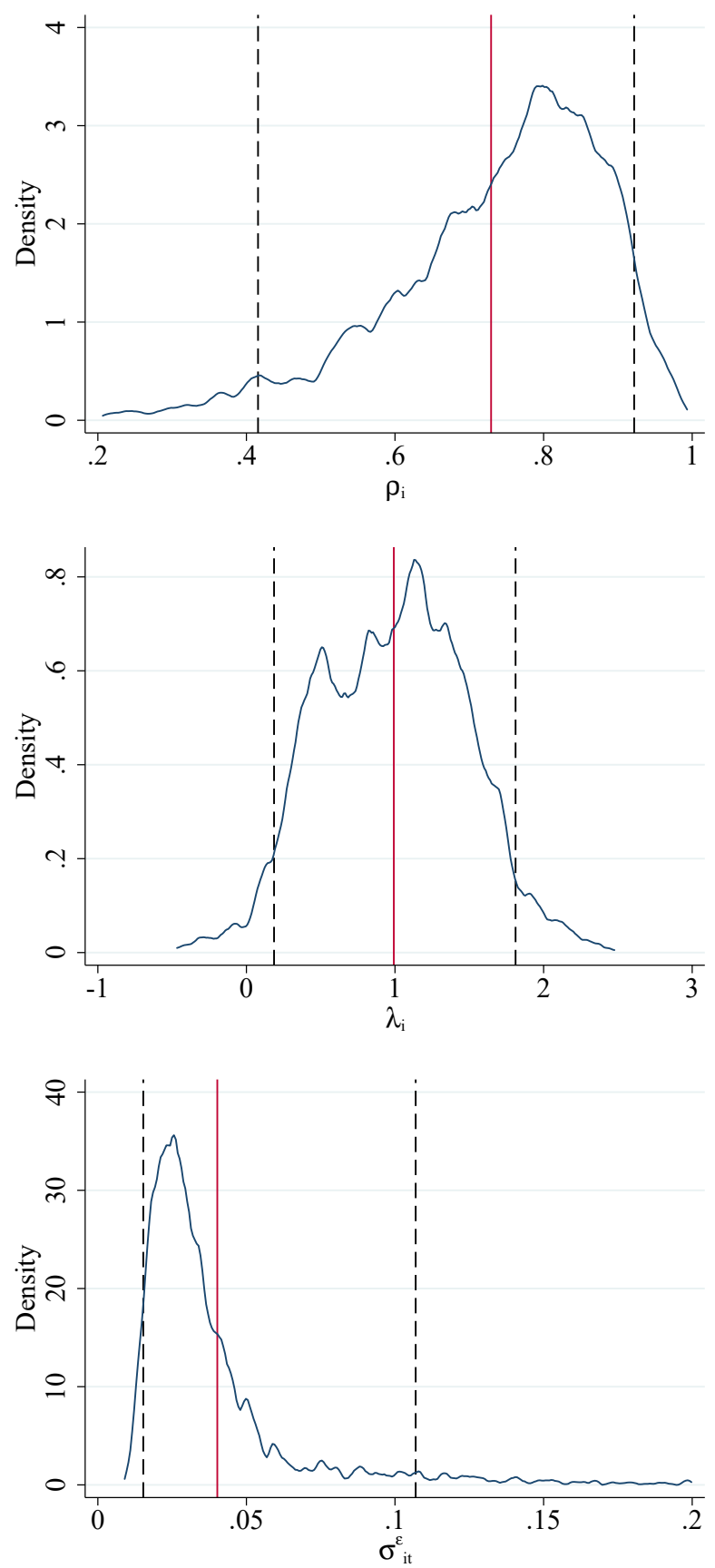

Note: This figure plots the kernel density distribution of estimates of selected parameters across all counties $i . \sigma_{i}^{\varepsilon}$ denotes the standard deviation of the income innovation $\varepsilon_{i t}$ over time for county $i$. 
Figure C.3: Estimated parameters - Private and Public

Private
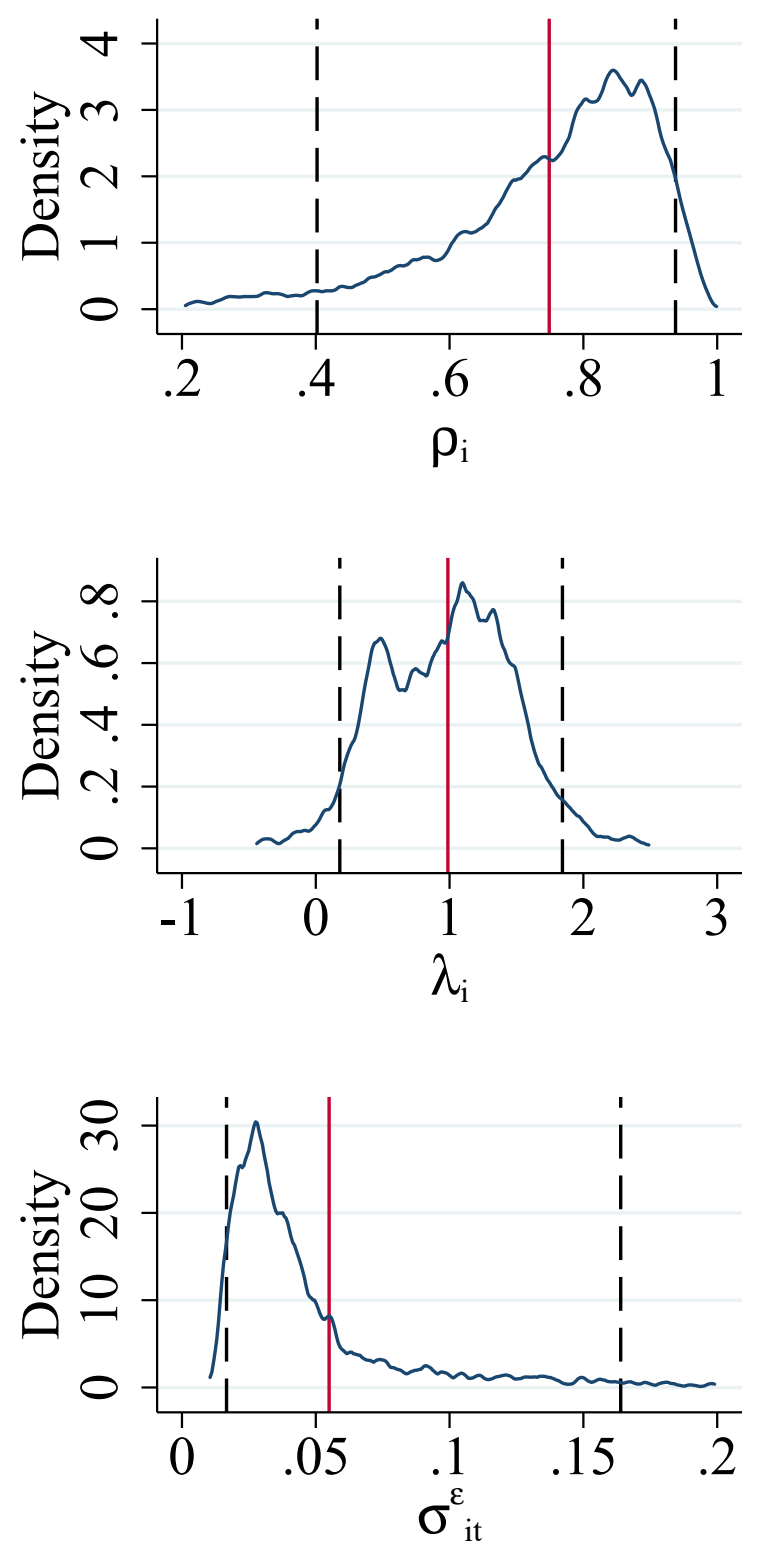

Public
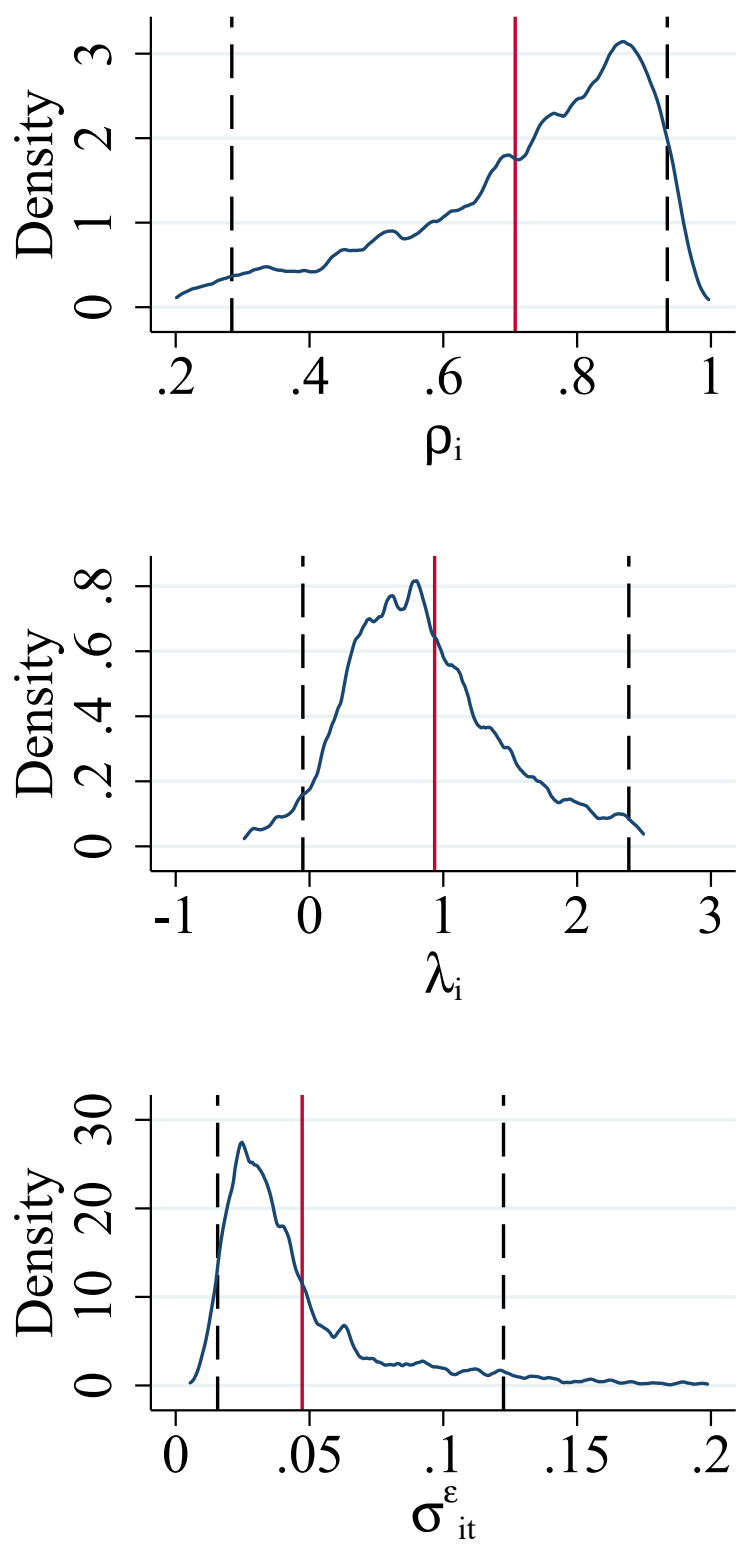

Note: This figure plots the kernel density distribution of estimates of selected parameters across all counties $i . \sigma_{i}^{\varepsilon}$ denotes the standard deviation of the income innovation $\varepsilon_{i t}$ over time for county $i$. 
Table A1: Moments of Shocks

(a) Standard Deviation

\begin{tabular}{lccc}
\hline \hline Sample: Great Recession 2007:Q4-2009:Q2 & Aggregate & Private & Public \\
\hline Macro Shocks $\left(\lambda_{i} \varepsilon_{t}\right)$ & 0.018 & 0.019 & 0.017 \\
Micro Shocks $\left(\varepsilon_{i t}\right)$ & 0.055 & 0.083 & 0.056 \\
Composite Shocks $\left(\lambda_{i} \varepsilon_{t}+\varepsilon_{i t}\right)$ & 0.059 & 0.085 & 0.058 \\
Common Shocks $\left(\varepsilon_{t}\right)$ without County Loadings $\left(\lambda_{i}\right)$ & 0.017 & 0.018 & 0.005 \\
& & & \\
Full-sample: 1990Q1-2018Q4 & & & \\
\hline Macro Shocks $\left(\lambda_{i} \varepsilon_{t}\right)$ & 0.015 & 0.017 & 0.012 \\
Micro Shocks $\left(\varepsilon_{i t}\right)$ & 0.055 & 0.085 & 0.061 \\
Composite Shocks $\left(\lambda_{i} \varepsilon_{t}+\varepsilon_{i t}\right)$ & 0.057 & 0.087 & 0.062 \\
Common Shocks $\left(\varepsilon_{t}\right)$ without County Loadings $\left(\lambda_{i}\right)$ & 0.013 & 0.014 & 0.009 \\
\hline \hline
\end{tabular}

(b) Cumulative Great Recession Shocks: First Moment

\begin{tabular}{lccc}
\hline \hline Sample: Great Recession 2007:Q4-2009:Q2 & Aggregate & Private & Public \\
\hline Macro Shocks $\left(\lambda_{i} \varepsilon_{t}\right)$ & -0.046 & -0.088 & 0.028 \\
Micro Shocks $\left(\varepsilon_{i t}\right)$ & -0.003 & 0.005 & 0.024 \\
Composite Shocks $\left(\lambda_{i} \varepsilon_{t}+\varepsilon_{i t}\right)$ & -0.049 & -0.083 & 0.053 \\
Common Shocks $\left(\varepsilon_{t}\right)$ without County Loadings $\left(\lambda_{i}\right)$ & -0.046 & -0.089 & 0.030 \\
\hline \hline
\end{tabular}


Figure C.4: Estimated Shocks to Private and Public County Wage Income
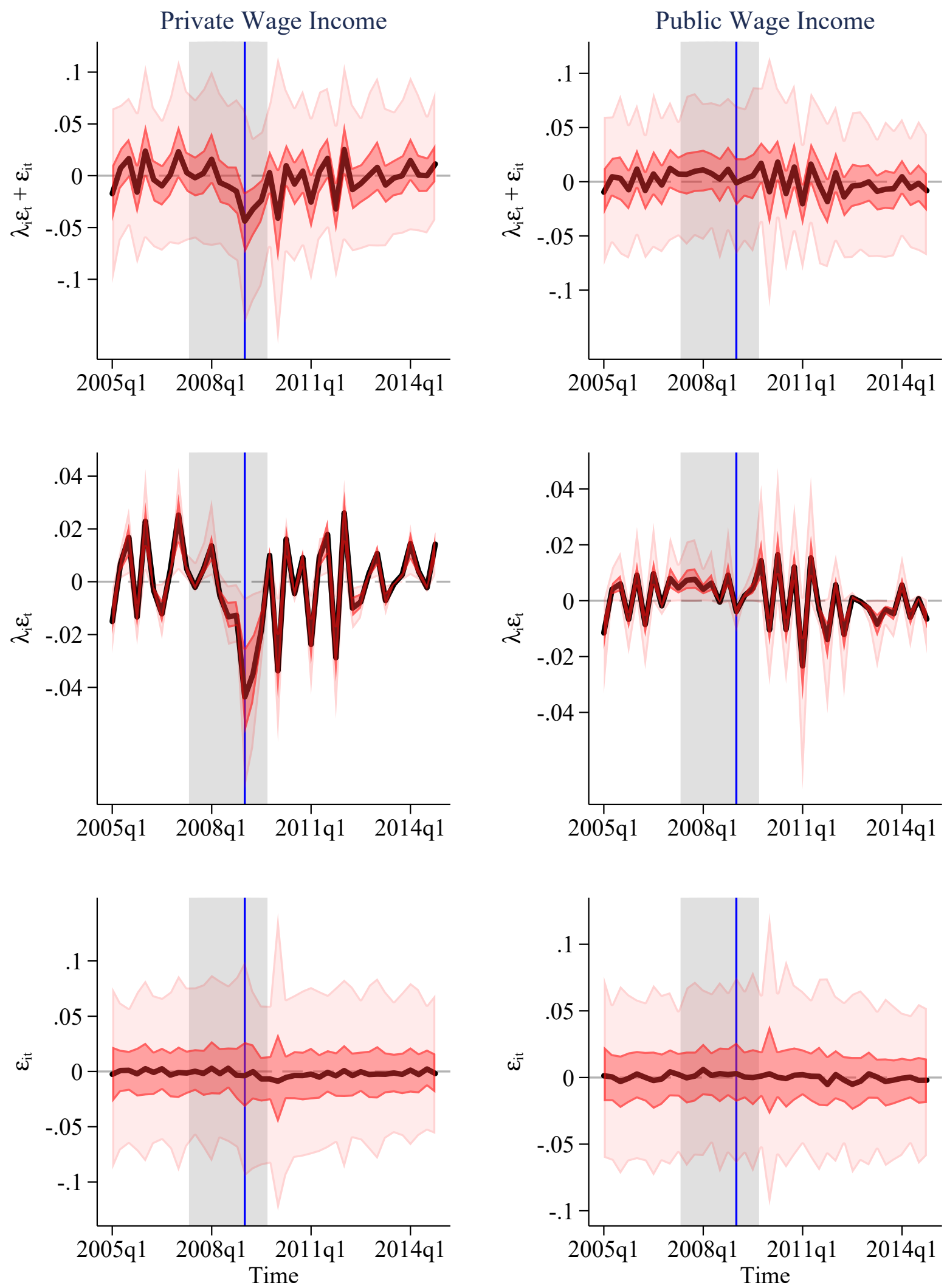

The blue lines denote ARRA Passage (2009 February). 